\title{
A CASE STUDY ON
}

MOST OPTIMAL POWER FLOW SOLUTIONS

TO SUPPLY POWER TO A NEW RESIDENTIAL COMPOUND LOAD LOCATED AT THE OUTSKIRTS OF AN INDUSTRIAL AREA BY USING THE OPTIMIZATION TOOLS

\author{
By \\ Nidal Abrahim Othman \\ Bachelor of Electrical Power Engineering, Jordan, 1994
}

The Project presented to

Ryerson University

in partial fulfillment of the requirements for the degree of Master of Engineering

\author{
in the Program of \\ Electrical and Computer Engineering (ECE) \\ Toronto, Ontario, Canada, 2011
}

C Nidal Abrahim Othman 2011 


\section{Author's Declaration:}

I hereby declare that I am the sole author of this project.

I authorize Ryerson University to lend this project to other institutions or individuals for the purpose of scholarly research.

Nidal Abrahim Othman

I further authorize Ryerson University to reproduce this project by photocopying or by other means, in total or in part, at the request of other institutions or individuals for the purpose of scholarly research.

Nidal Abrahim Othman 


\section{Borrow List}

Ryerson University requires the signatures of all persons using or photocopying this project.

Please sign below, and give address and date. 


\section{Acknowledgements}

I would like to thank my advisor Dr. Kaamran Raahemifar for his continued guidance and support throughout my Master's program. He has been a great mentor, and an excellent role model in research.

I would also like to thank all of my family members and my friends from Ryerson University for their support of me during my Master of Engineering program and project preparation. 


\section{Abstract}

Nidal Abrahim Othman, M.Eng. ECE, Ryerson University, Toronto, 2011.

This project studies different solutions, presents an efficient and reliable approach, to solve the optimal power flow (OPF) problem for an industrial power system by using fmincon optimization method and technique. This fmincon toolbox from MATLAB attempts to find a constrained minimum of a scalar function of several variables starting at an initial estimate. This is generally referred to as constrained nonlinear optimization or nonlinear programming.

The objective in OPF problem is to minimize the total cost function of generating units and the transmission losses, while maintaining the design and performance of the entire power system, satisfying the operational requirements such as the real and reactive power outputs of the generating units, bus voltages and power flow of transmission lines... etc.

This project presents the most optimal solution of power flow incorporating wind generation cost, to supply power to a new domestic load located at the outskirts of an industrial area for three different scenarios. This residential is typical of long rural line with isolated load area.

The challenge in our case study is to incorporate a wind generation unit as one type of green energy, that are currently being considered as an alternative source of power, to feed this long rural line for the domestic load without effecting in the total generation cost.

A case study is carried out for three different scenarios incorporating wind generation cost. The results of OPF in this project shows that incorporating wind generation unit as renewable energy source with the entire power system will have a minimum generation cost and minimum transmission losses for the entire power system even if the wind generation cost assumed to be the most expensive one comparing with other conventional generation units.

This project report provides implementation of Algorithm for the entire power load flow using the fast decoupled power flow (FDPF) and optimizes the best solution for the three different scenarios by using fmincon Interior Point Algorithm as one of optimization toolbox to achieve the minimum total cost function of generating units and minimum transmission losses. 


\section{Table of Contents}

INTRODUCTION .1

2 OPF DESIGN CHALLENGES. .2

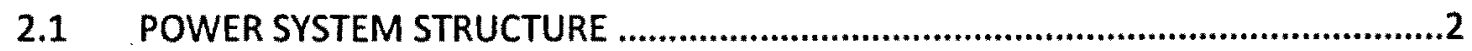

2.2 ELECTRICITY MARKET STRUCTURE \& DISPATCHING PRACTICE ..........................4

3 OPF SURVEYS . .7

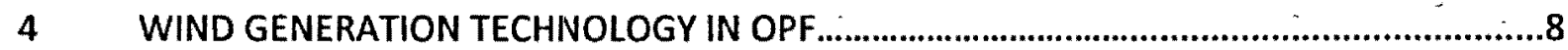

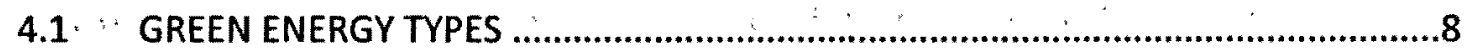

4.2 COST COMPARISONS OF GREEN ENERGY SUPPLY TECHNOLOGIES.................... . 9

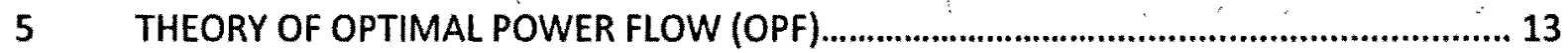

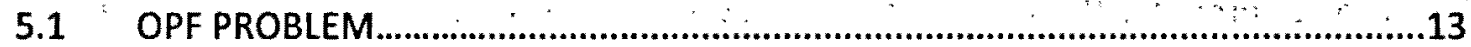

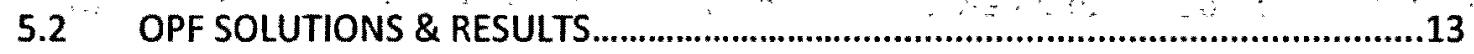

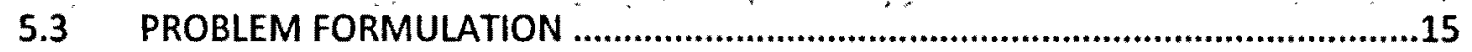

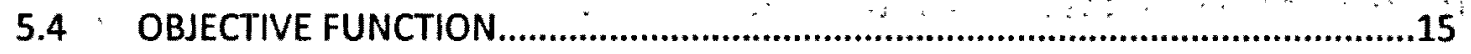

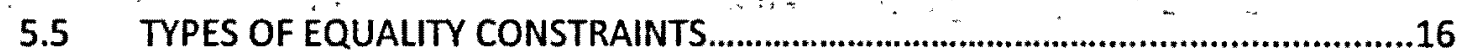

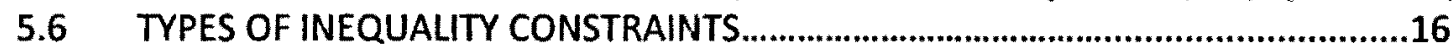

6 PROJECT CASEE STUDY USING OPF METHODOLOGY

6.1 DISCUSSION \& THEORY........................................................................ 18

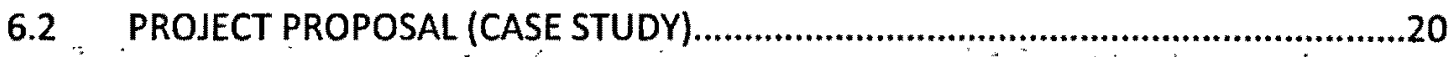

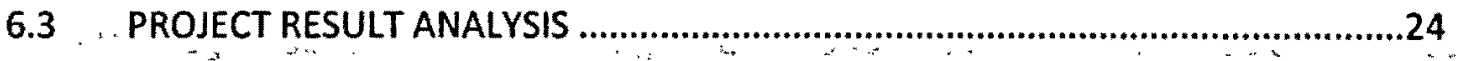

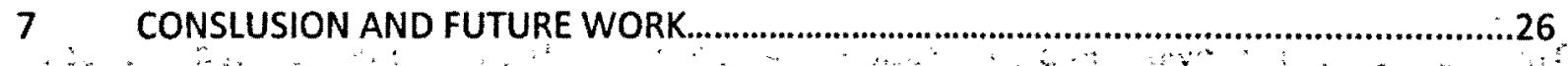

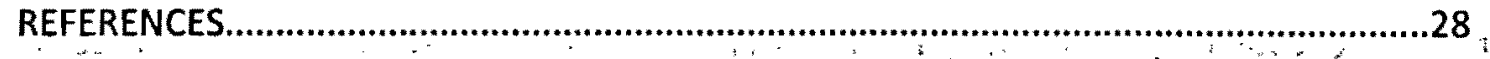

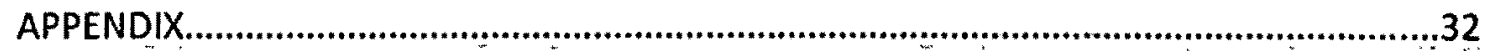




\section{List of Tables}

Table 1: Cost Comparisons of Energy Supply Technologies.

Table 2: Test Results Analysis for Three Different Scenarios

\section{List of Figures}

Fig.1: H.V. Transmission Lines Interconnection in Ontario Province..................................... 2

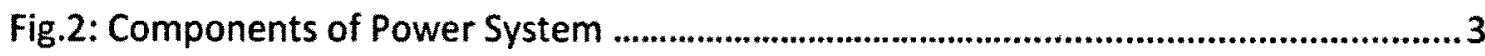

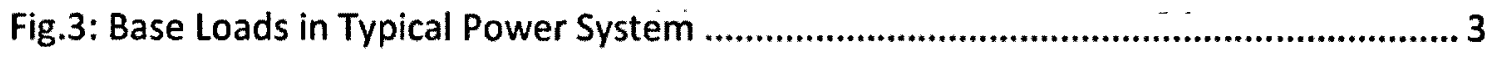

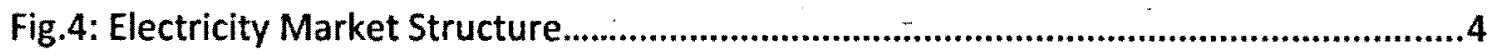

Fig.5: Typical Offer for Market Structure

Fig.6: Total Capital Costs for different types of green energy............................................. 11

Fig.7: Operational Costs for different types of green energy ....................................... 11

Fig.8: Net Yearly Cost (Life/Capital) including the Yearly Running Cost ............................. 12

Fig.9: Power Production Cost $(\$ / K W H)$ for different types of energy ................................. 12

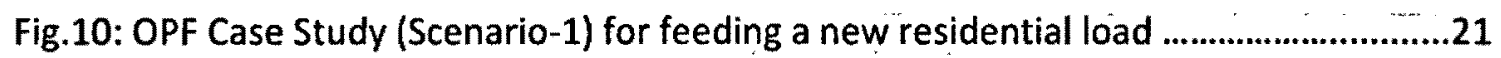

Fig.11: OPF Case Study (Scenario-2) for feeding a new residential load by a Wind Generation Unit with disconnected T.L with other generating units of the Industrial Area

Fig.12: OPF Case Study (Scenario-3) for feeding a new residential load from the entire power system with consideration of the Wind Generation cost.

Fig.13: Comparison of Total Generation Cost (\$/MW) based on OPF results 24

Fig.14: Comparison of Transmission Losses (MW) based on OPF results 


\section{List of Abbreviations}

\begin{tabular}{|c|c|}
\hline DMS : & Operation of the Distribution System in the ECC \\
\hline DOPF & Dynamic Optimal Power Flow \\
\hline DS & Distribution System \\
\hline ECC & Energy Control Center $\quad<\ldots, \ldots$ \\
\hline EMS & Energy Management System \\
\hline FDPF & Fast Decoupled Power Flow \\
\hline GA & Genetic Algorithms \\
\hline$\cdots$ & Gauss-Seidel \\
\hline IEEE & Institute of Electrical and Electronics Engineers \\
\hline ISO or IESO & Independent (Electricity) System Operator \\
\hline LDC & Load Dispatch Center \\
\hline LF & Lagrange's Function and multipliers \\
\hline$\therefore$ & Linear Programming $\quad, \quad, \cdots$ \\
\hline NG \& NB & Number of Generators \& Number of Buses \\
\hline NLP & Non-Linear Programming \\
\hline NR & Newton-Raphson \\
\hline $\begin{array}{llll}\text { OPF } & \cdots & \cdots & \cdots\end{array}$ & Optimal Power Flow \\
\hline SCADA $\quad \ldots \ldots \ldots \ldots$ & Supervisory Control and Data Acquisition \\
\hline SOPF & Static Optimal Power flow $\ldots$ \\
\hline TS $7, \ldots, \ldots$ & Transmission System \\
\hline TSO $\cdots \ldots$. & Transmission System Operator (TSO) $\ldots \ldots \ldots$ \\
\hline UC & Unit Commitment \\
\hline
\end{tabular}




\section{Introduction}

Optimal Power Flow (OPF) problem was given more attention in the past couple of decades, while the power industry worldwide develops towards a more competitive environment. The objective function in OPF is the operating cost of the generating units and the solution is the exact economic dispatch with the minimum generation cost and transmission losses [1].

OPF has been frequently solved using typical optimization method and technique on computer using MATLAB and different optimization toolbox like fmincon that has become standard practice to solve a lot of optimization problems. This toolbox from MATLAB has three algorithms, with several options for Hessians, including fmincon trust region reflective algorithm, fmincon active set algorithm, and fmincon interior point algorithm.

OPF problem for the power system is defined as a large scale, highly constrained, non-linear, non-convex optimization problem. OPF problem solution targets to optimize the generation cost as an objective function over optimal adjustment for control variables of power system, while satisfying different quality and inequality constraints. The equality constraints are the power flow equations, while the inequality constraints are the limits on the control variables (i.e. real power of generating units, generator bus voltages, reactive power of capacitor banks, transformer tap settings ...etc.) and operating limits of power system dependant variables, including load bus voltages, generator reactive power, and line power flows [2].

A required power system analysis (i.e. such as load flow analysis and unit commitment) often involves simulating the power system as it operates in a steady-state condition. OPF is an effective tool for performing these simulations [3].

OPF could be considered as the minimization of an objective function representing the generation cost and/or the transmission losses. The constraints involved are the physical laws controlling the power generation-transmission systems and the other operating limitations of the equipment [4]. 


\section{OPF Design Challenges}

Generally, the electrical power systems is one of the most complex systems built by mankind, in terms of physical size and the number of interacting variables. A large size of power system is very expensive and could cost around $400,000 \$ / \mathrm{km}[5-7]$.

Also, nodeling of a "Power System" is a comp!icated, challenging and difficult task. Fig. 1 shows the high voltage transmission lines interconnection in Ontario Province in Canada, as a good example for a power system structure.

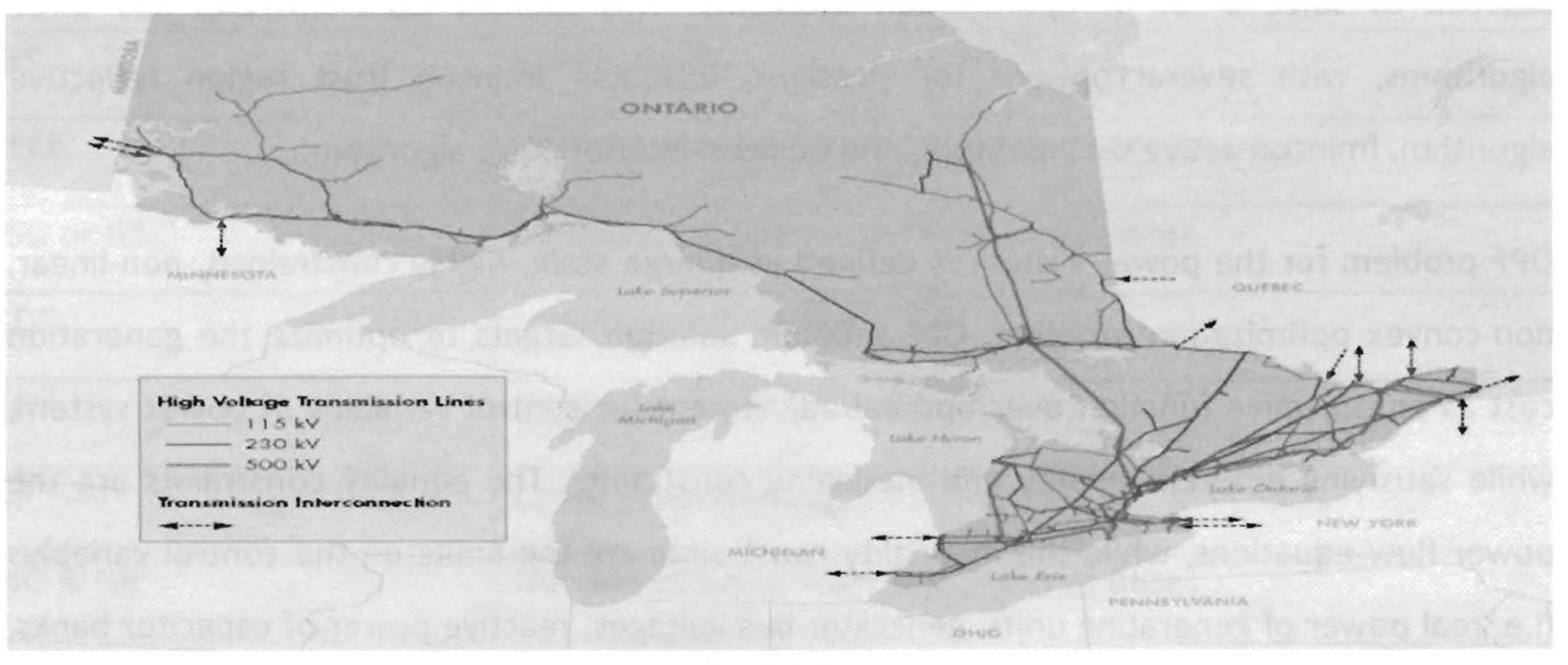

Figure 1: H.V. Transmission Lines Interconnection in Ontario Province from [7]

\subsection{Power System Structure:}

The main components of any power system shown in Fig. 2 are including the following:

a) Generation Units.

b) Transmission System (TS): include the main transmission system, distribution systems, inter-system tie lines and transformers.

c) Loads: Power system satisfies energy requirements of modern society, cities that comprise mainly of air-conditioning and lighting load, industrial towns that mostly have induction motor loads and other large electrical power consumers). 
d) Main Energy Control Center (EEC): Independent System Operator (ISO) is responsible for controlling the "Power System Optimization" and "Unit Commitment (UC)"...etc [5-7]

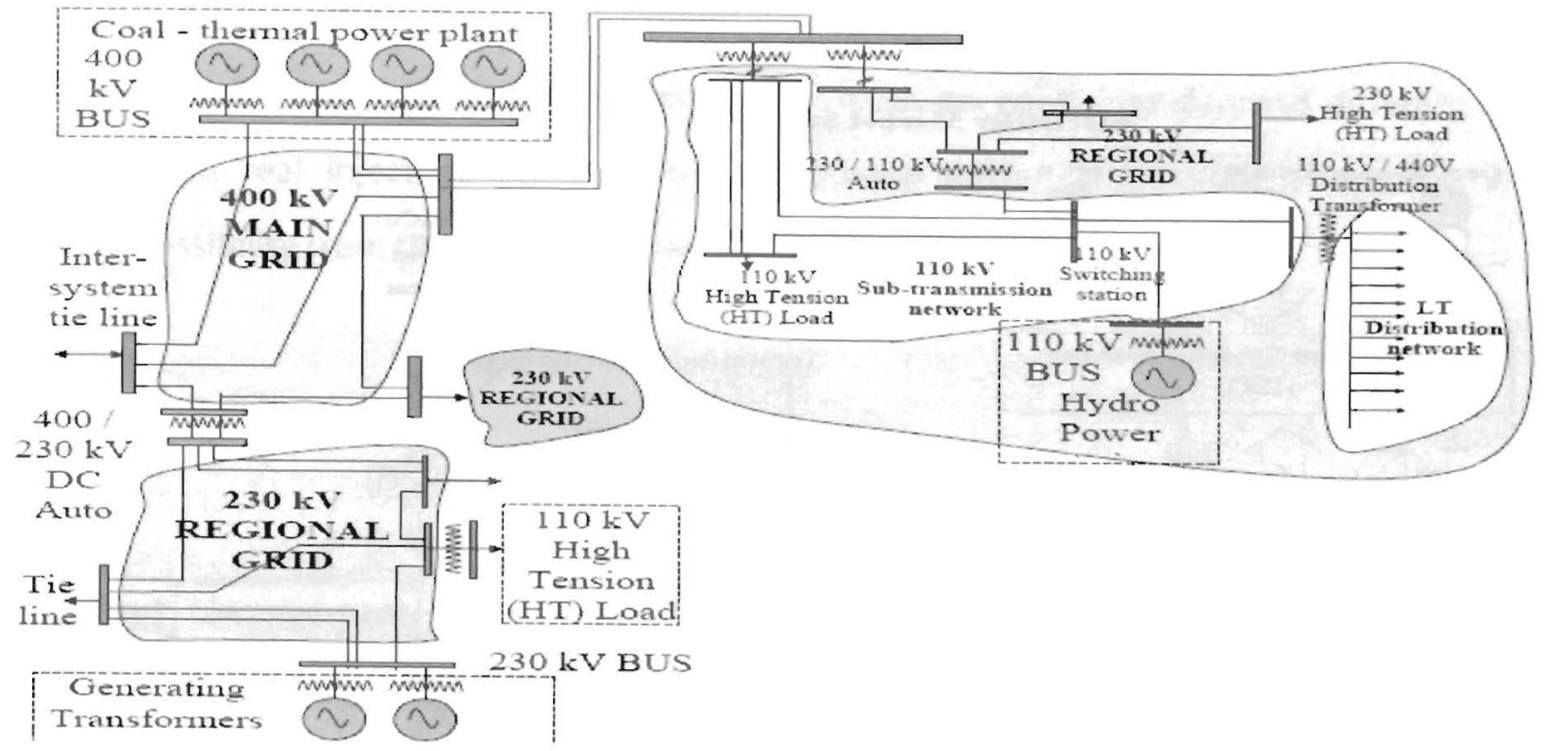

Figure 2: Components of Power System from [7]

Loads in the power system may be categorized in several ways. Fig. 3 shows the first categorization that breaks them to:

a) Domestic Loads: lighting, fans, TV, Air Conditioners, etc.

b) Industrial Loads: induction motor loads, lighting loads, air conditioners, resistive neating loads and other appliances [5-7].

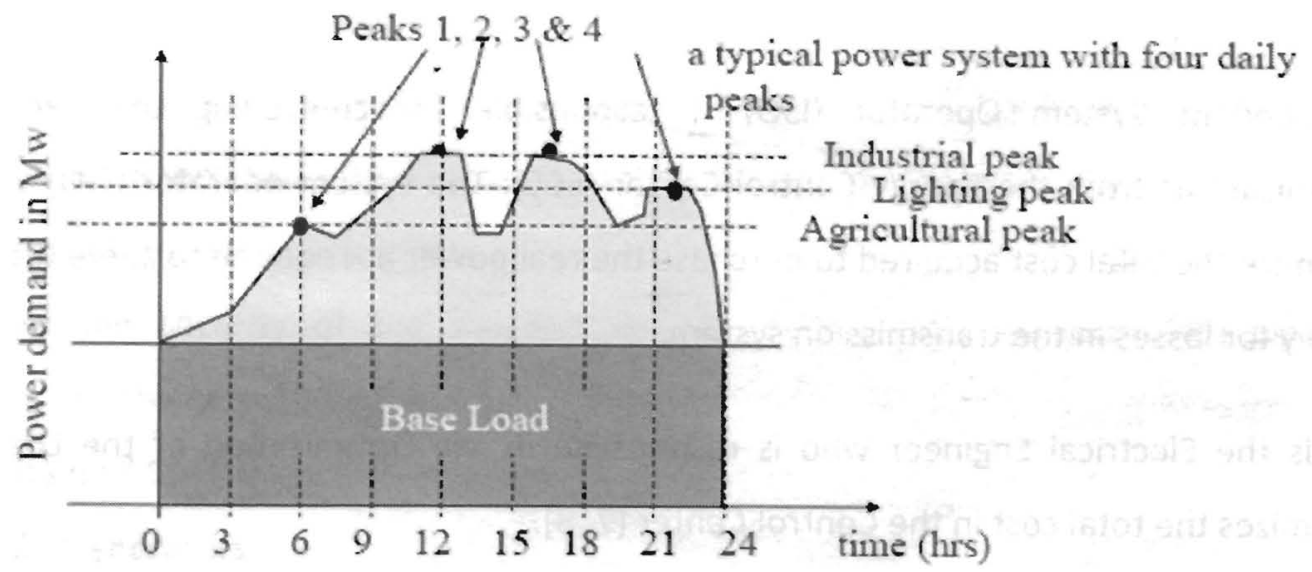

Figure 3: Base Loads in Typical Power System from [7] 


\subsection{Electricity Market Structure \& Dispatching Practice:}

The Electricity Market Structure has two different models as shown in Fig.4.

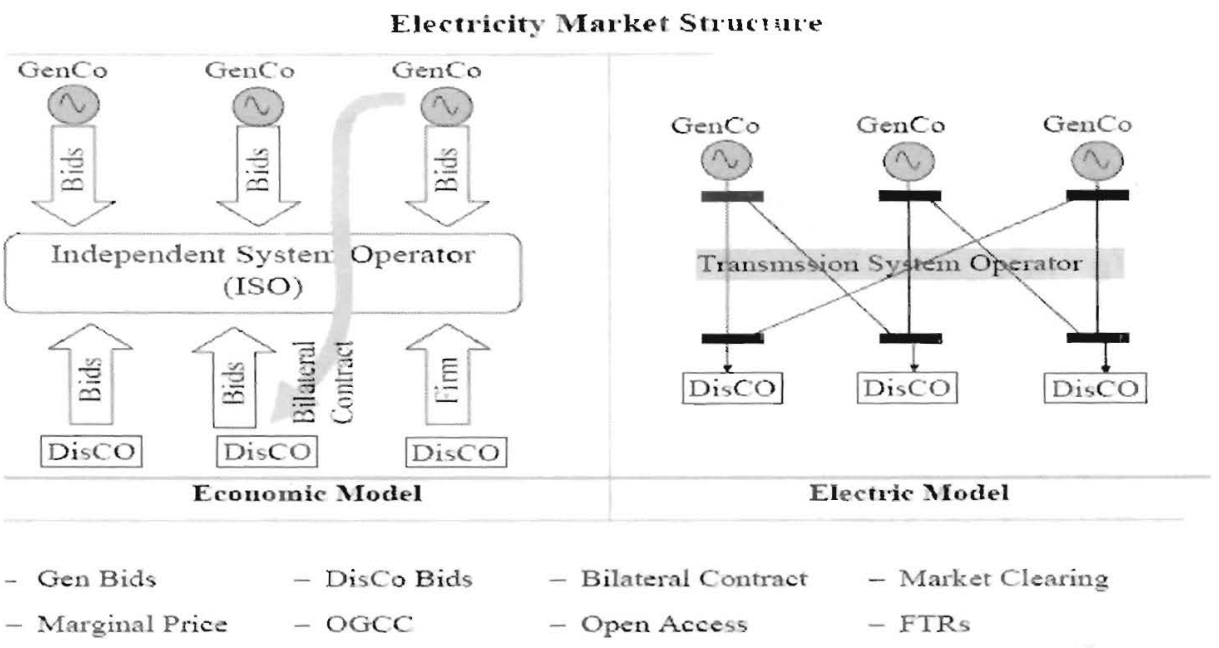

Figure 4: Electricity Market Structure from [7]

The Electric Model / Structure in the market structure depending on Transmission System Operator (TSO) to operate the power system with the minimum generation cost and low transmission losses and to meet the criteria of the entire power system as well as to balance this needs between the distribution and the generation companies.

The other model is the Economic Model / Structure in the market structure depending on the Independent System Operator.

Independent System Operator (ISO) is responsible for controlling the "Power System Optimization" from the Energy Control Center (ECC). The system operator (ISO) would like to minimize the total cost acquired to purchase the real power as required to serve the load(s) and supply for losses in the transmission system.

ISO is the Electrical Engineer who is responsible in the Optimization of the Load Flow and minimizes the total cost in the Control Center $[7,8]$. 
Fig. 5 shows a typical example of an offer presented for Market Structure by the producers. The same economical offers are used both for day-ahead operational planning and for real time operation at the command system for balancing reasons. The reasons for the need of a real time re-dispatching could be for different reasons such as: consumer demand different from load forecast, real injection different from scheduled power production, generation units tripping possibility from time to time, ...etc. [9]

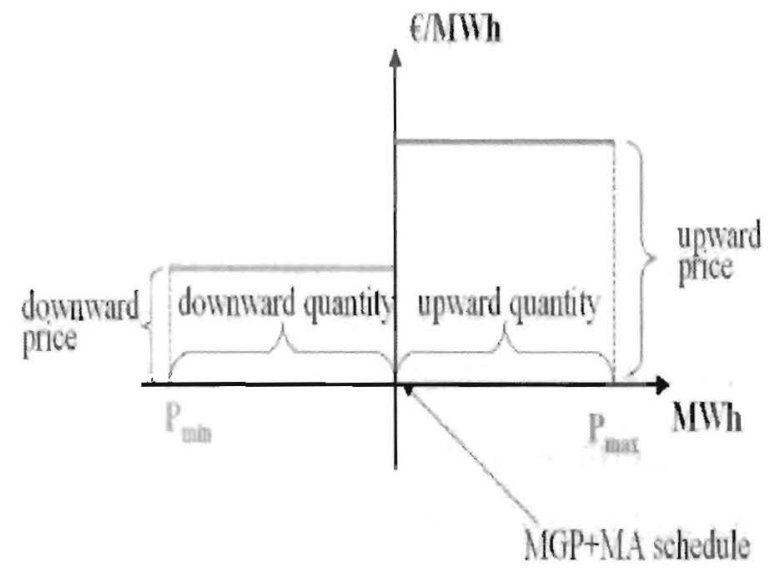

Figure 5: Typical Offer for Market Structure from [9]

Energy Control Center (ECC) role and responsibility emphasizing on safety, quality, reliability, and economy, are the key elements to control the operation of any electrical power system. The following tasks are performed to operate the power system with minimum generation cost and low transmission losses and to meet the criteria [8-10]:

1. Maintain the balance between load and generation.

2. Maintain the reactive power balance in order to control the voltage profile.

3. Maintain an optimum generation schedule to control the cost and environmental impact of the power generation.

4. Ensure the security of the network against reliable contingencies. This requires protecting the network against reasonable failure or shutdown of the power system.

5. Maintain all Controllable items:
a) Generators
b) Transmission System (TS)
c) Distribution System (DS) 
6. Person in-charge: "Load Dispatcher" and "Independent System Operator (ISO)".

7. Schedules all the generating stations power output.

8. Controls other critical controls of the system like transformer taps setting, etc.

9. Monitors through a system called Supervisory Control and Data Acquisition (SCADA). Takes corrective action as required.

10. Office is referred to as the Energy Control Center or Load Dispatch Center (LDC).

In case the loads and networks configuration changed, the state of the power network will not change, which makes it more difficult to operate the power system. Also, the response of many power network machines is not prompt. That's why changing trends and growth have increased the need for computer-based operator support in interconnected power systems [8-10].

Two control centers are normally implemented in EEC are (EMS) for the operation of the generation-transmission system, and (DMS) for the operation of the distribution system, which is intended to help the dispatchers in monitoring and control of the system. The simplest of such systems perform the function of SCADA (supervisory control and data acquisition system) and others may have other sophisticated power application functions. The SCADA system accepts telemetered data and displays them to operators has an alarm management subsystem that monitors informs the operators of abnormal conditions [8-10].

Energy Management System (EMS) assists the operator (ISO) in monitoring and control of the electrical network with power application software and contains all the features of SCADA systems in data acquisition, control and monitoring, Load management, loss minimization, peak shaving and load shifting are some important activities of EMS implemented [8].

EMS and SCADA systems consist of a networked architecture of computers performing online computations with backup support. EMS functions can be categorized as base functions, generation functions, and network functions [8].

Market structures are essentially related to active power scheduling for the current practice in the day that ahead of energy market, defining the Unit Commitment (UC) of the generating units as well as the relevant dispatching that complying with transmission constraints $[9,10]$. 


\section{OPF Surveys}

Comprehensive Surveys considered for a lot of papers in the field of optimal power flow (OPF). In this project, different approaches to solve the OPF problem for any power system were studied. Each technique and method will have its Pros and Cons.

Optimization methods and techniques, which have been used in solving the OPF problems, have wide variety of techniques, such as Newton-Raphson (NR) based techniques [11, 12], interior point methods $[13,14]$, quadratic programming $[15,16]$, non-linear (NLP) programming [17-21], linear programming (LP) [22-24], sequential unconstrained minimization technique [25] and other different practical techniques of optimization from different surveys [26-29].

Effective OPF is limited first by the high dimensionality of power systems, and second by the incomplete domain dependent knowledge of power system engineers. The first limitation is addressed by numerical optimization procedures based on successive linearization using the first and the second derivatives of objective functions and their constraints as different searches directions or by linear programming solutions to imprecise models. From the practical methods of optimization was stated that the advantages of such methods are in their mathematical foundation, but disadvantages exist also in the sensitivity to problem formulation, algorithm selection and usually converge to local minima. The second limitation, incomplete domain knowledge, prevents also the reliable use of expert systems where rule completeness is not possible [4].

One of the Optimization methods is Linear Programming (LP) and Non-Linear Programming (NLP). LP and NLP offer a powerful technique to most of power system optimization problems by increasing the availability of high performance computers at relatively low costs [17-24]. On other hand, LP and NLP optimization technique solve global optimization searching problems by using Newton Raphson (NR) or Gauss-Seidel (GS) as well as Lagrange's Function and multipliers (LF) in case of NLP [4]. Also, the application of the Lagrange's Approach could be utilized as an optimization algorithm for NLP in the Optimal Power Flow [27]. 


\section{Wind Generation Technology in OPF}

One of the most important challenges in the current and coming years is the optimization control, like the optimal power flow (OPF) including wind generation technology and with consideration of the wind generation cost [30-37].

Dynamic optimal power flow (DOPF) is "a typical complex, multi-constrained, non-convex, nonlinear programming problem in wind power integrated system" [37].

\subsection{Green Energy Types:}

There are different sources of Energy such as Fossil Fuels (i.e. coal, Natural gas and diesel), Nuclear Power, Hydro Electric Power and the green power [30]. Also, there are a lot of comprehensive surveys in the Renewable Energy types as a green power generation. From the Wikipedia references, we could summarize the types of Green Energy as below:

Green energy is created from natural resources that do not cause harmful pollution to Earth's surface or atmosphere. With the concern of global warming and reducing the natural resources, environmentally friendly alternatives are needed. Earth's sun, water and wind power have been used to operate machinery and generate power since ancient times. "The different types of green energy that are currently being considered as alternative sources of power could be described as below [30]:

1. Hydropower converts water from rivers into usable energy released from turbines. Today, it is considered very expensive and difficult to build hydropower plants to produce mass amounts of electricity. There are also concerns that their usage may affect wildlife and change the quality of the water [30].

2. Geothermal energy is produced from steam or hot water from under the Earth's surface. The steam powers electric generators by rotating turbines. One use for it is heating buildings. It is not widely available due to the lack of natural land sites. There are also concerns that geothermic fields may eventually reduce. It is a green energy due 
to its low emissions. Its production is not affected by weather changes and can continuously work day and night. There are also some concerns about geothermal fields affecting the surrounding land's stability [30].

3. Wind energy can be used to create energy by rotating large propellers like blades around a hub. The blades slow down the speed of the wind it captures and channels it to a generator that produces electricity. Wind energy usage worldwide is very small; the technology is expensive and its machinery is considered to be noisy. The energy it produces generates no pollution and has been used to power homes and farms [30].

4. Solar energy is another form of green energy. Photovoltaic cells can absorb light from the sun to capture electrons and use them to generate electricity. The sun has been used as a source of energy since ancient times. However, it is still considered to be expensive due the cost to produce the photovoltaic celled panels needed to generate energy. These types' panels are usually large and take up a lot of space. Solar energy is also inconsistent and needs a large surface area to generate enough electricity on a large scale. Solar energy is being used to power some homes, cars and in agriculture.

5. Hydrogen is another source of energy that is eco-friendly. It's a common element that can produce an unlimited amount of energy using water and electricity. Hydrogen was once thought to be too dangerous to work with, but it is now being considered as a source of fuel for vehicles. No emissions are created when used in its purest form. Only water is released as a result. It is expensive to produce and store. More research and time will be needed before it could be used on a worldwide scale" [30].

\subsection{Cost Comparisons of Green Energy Supply Technologies:}

It is well known that the conventional OPF problem only involved the thermal energy power sources [31]. However, with the introduction and development of the renewable energy sources specifically the wind energy [32] started the necessity to incorporate the wind generation cost into the classical OPF problem. Several of literature [31- 37] have been published in investigating the OPF problem with wind generation cost involved. 
The Electricity Generation costs estimates based on a single station developed with a prototype built and tested, as shown in Table 1, based on the reference from the website of the cost comparisons of energy supply technologies [38]. From this website, we have a got a chance to compare the electricity generation costs for numerous green energy supply technologies.

Table 1: Cost Comparisons of Energy Supply Technologies, dated April 28th, 2011 from [38]

\begin{tabular}{|c|c|c|c|c|c|}
\hline $\begin{array}{l}\text { Energy Supply } \\
\text { Technology Type }\end{array}$ & Coal Fired & Nuclear & Solar Tower & $\begin{array}{c}\text { Geothermal } \\
\text { Steam }\end{array}$ & Wind Farms \\
\hline $\begin{array}{l}\text { Estimated Life Cycle } \\
\text { (in years) }\end{array}$ & 25 years & 25 years & 60 years & 15 years & 25 years \\
\hline Gross output & $1000 \mathrm{MW} / \mathrm{hr}$ & $1000 \mathrm{MW} / \mathrm{hr}$ & $200 \mathrm{MW} / \mathrm{hr}$. & $300 \mathrm{MW} / \mathrm{hr}$. & $200 \mathrm{MW} / \mathrm{hr}$. \\
\hline Net output (MW/hr.) & 900 & 815 & 195 & 270 & 190 \\
\hline Output efficiency & $90.00 \%$ & $81.50 \%$ & $97.50 \%$ & $90.00 \%$ & $95.00 \%$ \\
\hline \multicolumn{6}{|l|}{ CAPITAL COSTS } \\
\hline Design Cost & $\$ 100 M$ & $\$ 750 \mathrm{M}$ & $\$ 150 M$ & $\$ 250 \mathrm{M}$ & $\$ 100 M$ \\
\hline Test Plant & Not required & $\$ 1,000 \mathrm{M}$ & $\$ 150 \mathrm{M}$ & $\$ 500 \mathrm{M}$ & Not required \\
\hline $\begin{array}{l}\text { Materials/Equipment } \\
\text { Cost }\end{array}$ & $\$ 700 M$ & $\$ 1,000 \mathrm{M}$ & $\$ 400 M$ & $\$ 550 M$ & $\$ 800 M$ \\
\hline Construction Cost & $\$ 250 \mathrm{M}$ & $\$ 500 \mathrm{M}$ & $\$ 250 \mathrm{M}$ & $\$ 350 \mathrm{M}$ & $\$ 300 \mathrm{M}$ \\
\hline Labour Cost & $\$ 250 \mathrm{M}$ & $\$ 500 \mathrm{M}$ & $\$ 90 M$ & $\$ 200 \mathrm{M}$ & $\$ 150 \mathrm{M}$ \\
\hline Total Capital Costs & $\$ 1,300 M$ & $\$ 3,750 \mathrm{M}$ & $\$ 1,040 \mathrm{M}$ & $\$ 1,850 M$ & $\$ 1,350 M$ \\
\hline \multicolumn{6}{|l|}{$\begin{array}{c}\text { OPERATIONAL } \\
\text { COSTS }\end{array}$} \\
\hline Interest@6\% & $\$ 78 \mathrm{M}$ & $\$ 225 \mathrm{M}$ & $\$ 62.4 \mathrm{M}$ & $\$ 111 \mathrm{M}$ & $\$ 81 \mathrm{M}$ \\
\hline Fuel Cost & $\$ 200 \mathrm{M}$ & $\$ 400 M$ & $\$ 0$ & $\$ 0$ & $\$ 0$ \\
\hline $\begin{array}{l}\text { Fuel Waste Disposal } \\
\text { Cost }\end{array}$ & $\$ 100 M$ & $\$ 250 M$ & $\$ 0$ & $\$ 30 M$ & $\$ 0$ \\
\hline $\begin{array}{l}\text { Water use (including } \\
\text { mining process) }\end{array}$ & $\$ 100 \mathrm{M}$ & $\$ 300 M$ & $\$ 250 M$ & $\$ 15 M$ & $\$ 0$ \\
\hline Maintenance Costs & $\$ 150 M$ & $\$ 375 \mathrm{M}$ & $\$ 10 \mathrm{M}$ & $\$ 50 \mathrm{M}$ & $\$ 100 \mathrm{M}$ \\
\hline $\begin{array}{l}\text { OPERATIONAL } \\
\text { COSTS }\end{array}$ & $\$ 628 M$ & $\$ 1,550 M$ & $\$ 322.4 M$ & $\$ 206 \mathrm{M}$ & $\$ 181 M$ \\
\hline \multicolumn{6}{|l|}{ TOTAL COSTS } \\
\hline $\begin{array}{l}\text { Net Yearly Cost } \\
\text { (Life/Capital) }+ \text { Yearly } \\
\text { Running Cost }\end{array}$ & $\$ 1,271.3 M$ & $\$ 1,502.8 M$ & $\$ 1,875.2 \mathrm{M}$ & $\$ 89.983 M$ & $\$ 131.417 M$ \\
\hline $\begin{array}{c}\text { Production Cost } \\
\$ / K W H\end{array}$ & $\$ 0.16$ & $\$ 0.26$ & $\$ 0.05$ & $\$ 0.15$ & $\$ 0.14$ \\
\hline
\end{tabular}


As shown in Table 1, the electricity generation costs for different type of energy is estimated based on a single station developed with a prototype built and tested. The Total Capital Costs for the Nuclear power plant is the most expensive one comparing with other types of energy, as shown in Fig.6.

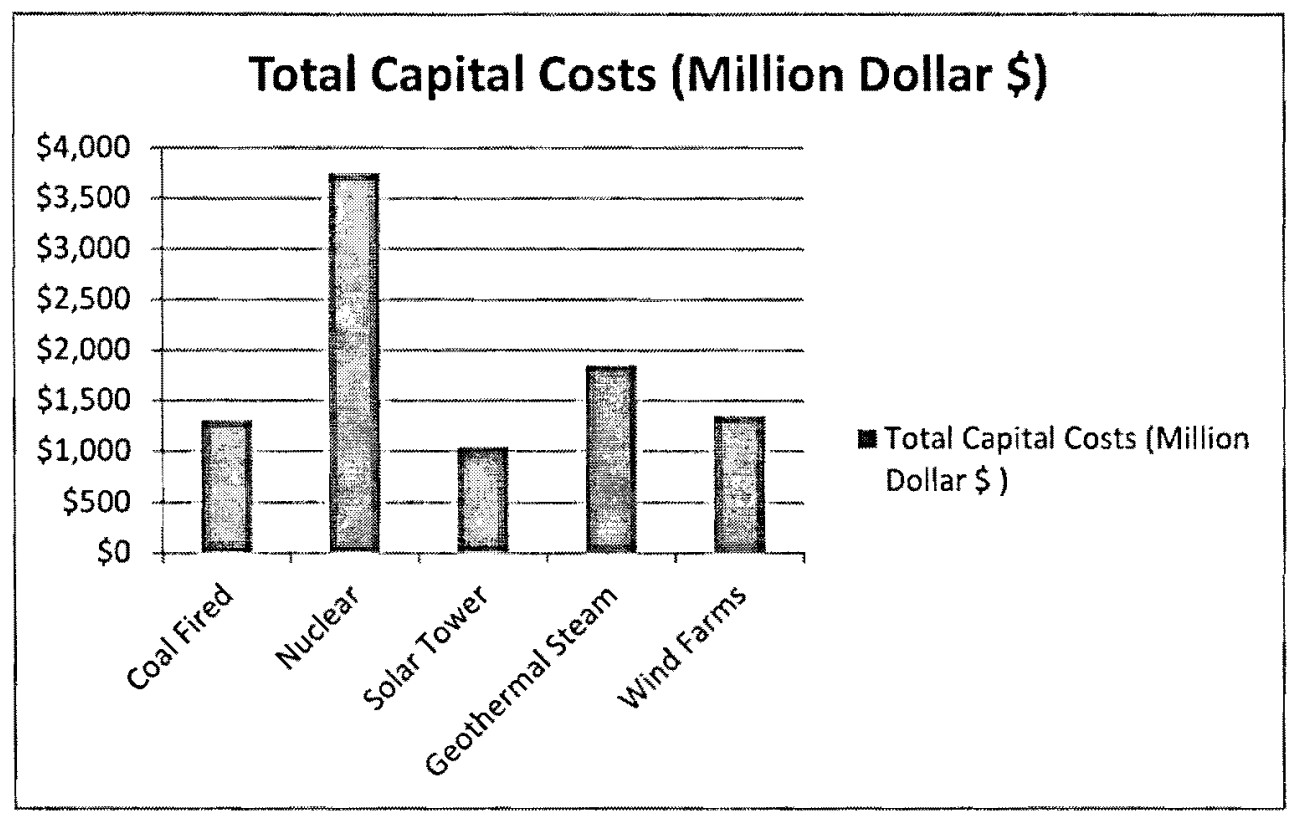

Figure 6: Total Capital Costs (M\$) for different types of energy

As show in Fig.7, also the Operational Costs for the wind generation is the minimum. However, the Nuclear power is the most expensive one comparing with other types of energy.

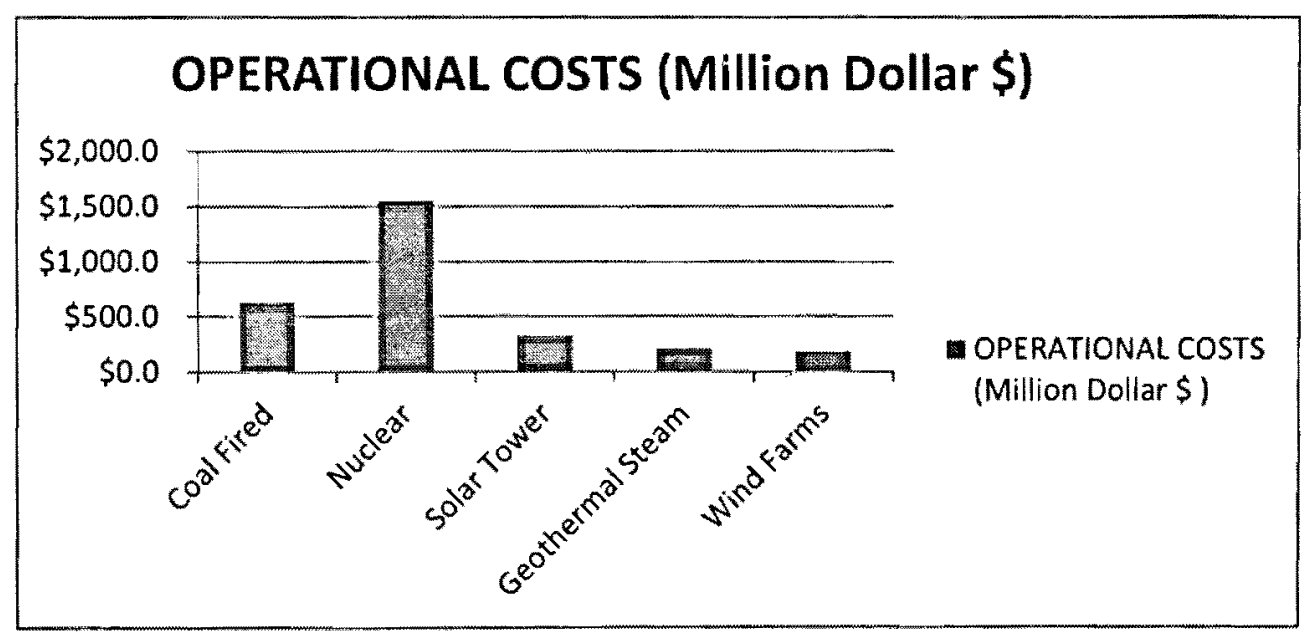

Figure 7: Operational Costs (M\$) for different types of energy 
Generally, the Nuclear power energy has the most expensive total capital cost to establish a nuclear power plant as well as the most expensive operational costs comparing with other power generation plants. However, the net yearly cost (life/capital) including the yearly running cost could be considered as economic power generation unit comparing with some other conventional energy. On other hand, it was very clear that the green energy especially the wind generation is considered as economical cost generation, as shown in Fig.8.

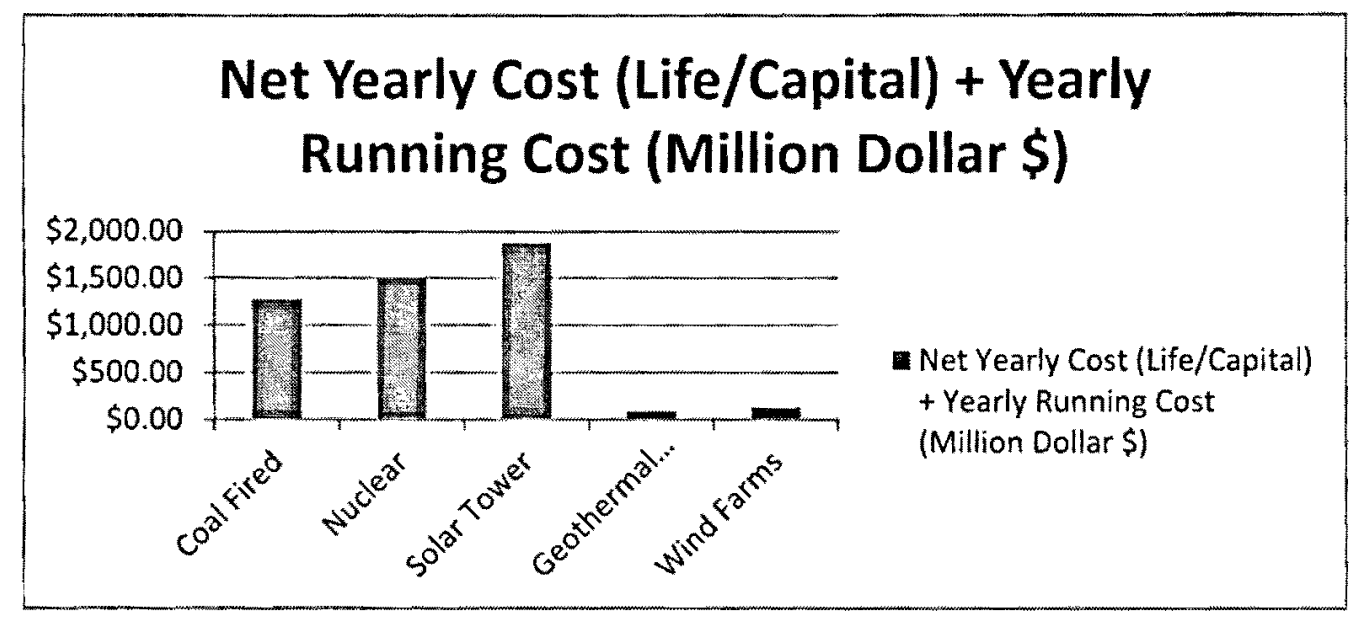

Figure 8: Net Yearly Cost (Life/Capital) including Yearly Running Cost (M\$) for different types of energy

Generally, one of the most important challenges in the current and coming years is the OPF including wind generation technology and the consideration of the wind generation cost in the OPF for the entire power system as in our case study. The wind generation cost based on the reference from the website of the cost comparisons of energy supply technologies, dated on April 28th, 2011 [38], is estimated as $0.14 \$ / \mathrm{KWH}$ for the production cost, as shown in Fig.9.

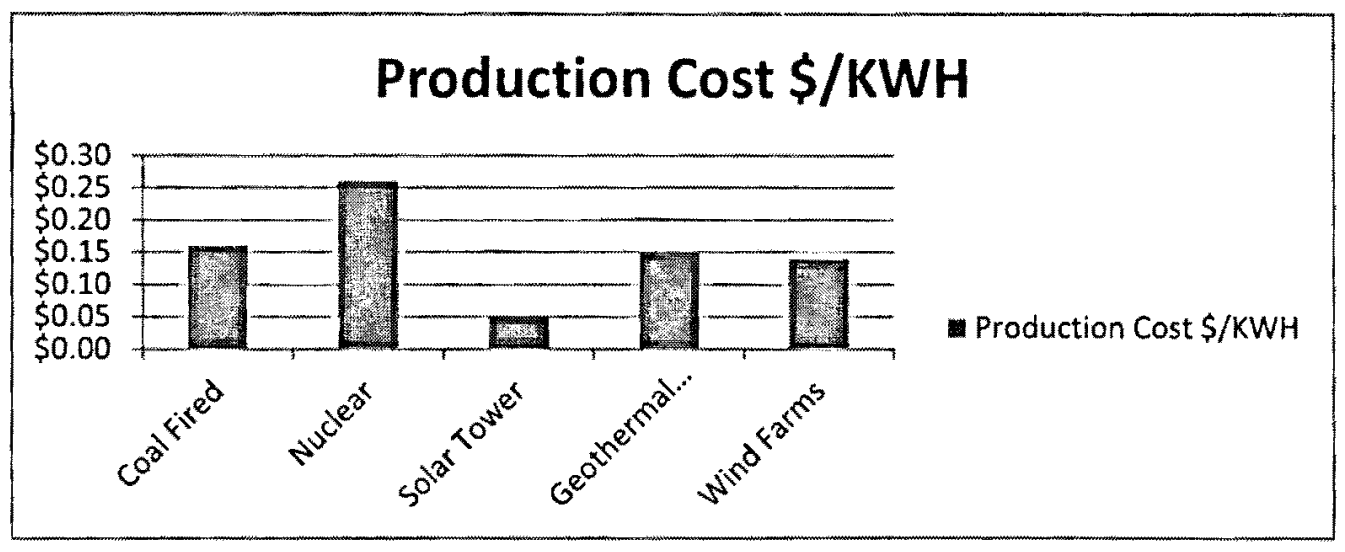

Figure 9: Power Production Cost $(\$ / K W H)$ for different types of energy and power generation plants 


\section{THEORY OF OPTIMAL POWER FLOW (OPF )}

During the comprehensive surveys that considered a lot of papers in the field of optimal power flow (OPF). I have found that one of the best researchers that explained the OPF theory in a very organized way is Tarek BOUKTIR and Linda SLIMANI [4], in addition to what learned during the course of Power System Optimization Course [7] and other survey papers in the field of OPF [11-29].

In this project, and from thoroughly study for different surveys, different approaches to solve the OPF problem for any power system were studied.

\subsection{OPF Problem:}

The Optimal Power Flow (OPF) has been usually considered as the minimization of an objective function representing the generation cost and/or the transmission losses. The constraints involved are the physical laws that leading the power generation and transmission systems, as well as the operating limitations of the entire power system and equipment [4-29].

\subsection{OPF Solutions \& Results:}

Effective Optimal Power Flow is limited by the high dimensionality of power systems and the incomplete domain dependent knowledge of power system engineers. [4-29]

A practical method is given for solving the Power Flow problem with control variables such as real and reactive power and transformer ratios automatically adjusted to minimize instantaneous costs or losses. The solution is feasible with respect to constraints on control variables and dependent variables such as load voltages, reactive sources, and tie line power angles. The method is based on power flow solution by Newton's (NR) method which modified to Fast Decoupled Power Flow (FDPF) as in the commercial use. 
Due to its quadratic convergence, the NR method that have modified to Fast Decoupled Power Flow, has rapid convergence independent from system size. However, as the system size (number of equations) increases, the function evaluation at each iteration will be increased.

Comparison between three different scenarios for our case study is done by using Fast Decoupled Power Flow (FDPF) with a result that shows the performance of FDPF. All results and data will be discussed later on in this project. Also, full study is done on our case study for three different scenarios for power load flow computation. The code can implement the Algorithm of the power load flow using the FDPF and find the maximum mismatch in the control variables of the real and reactive power for any number of buses that let the algorithm to converge.

The challenge in algorithm development is to efficiently identify the binding inequalities. This logarithmic corresponding to the original problem (OPF) is solved by the FDPF method.

The advantages of such methods are in their mathematical foundation, but disadvantages exist also in the sensitivity to problem formulation, algorithm selection and usually converge to local minima. The second limitation, incomplete domain knowledge, prevents also the reliable use of expert systems where rule completeness is not possible.

During the comprehensive survey in the OPF field and in the development and adaptive algorithms, some of the Optimization methods considered as a good optimization tools for the OPF such as Linear Programming (LP) and Non-Linear Programming (NLP). LP and NLP offer a powerful approach to these Optimization Problems made possible by the increasing availability of high performance computers at relatively low costs. Also, LP and NLP optimization technique solve global optimization searching problems by using Newton Raphson or Gauss-Seidel as well as Lagrange's Function and multipliers in case of NLP. The controllable variables are decomposed to active constraints that effect directly the cost function are included in the NLP and passive constraints which are updating using a conventional load flow program, only, one time after the convergence. The slack bus parameter would be recalculated in the load flow process to take the effect of the passive constraints [4]. 


\subsection{Problem Formulation:}

The standard OPF problem can be written in the following form [1-38],

Minimize : $F(x)$

Subject_to: $x_{\min } \leq x \leq x_{\max }$

$g_{i}(x)=b_{i} \forall i=1,2 \ldots M E$

$h_{i}(x) \leq c_{i} \forall i=1,2 \ldots M I$

where $F(x)$ is the objective function, $g(x)$ represents the equality constraints, $h(x)$ represents the inequality constraints and is $\mathrm{x}$ is the vector of the control variables, that is those which can be varied by a Control Center Operator (e.g. generated active and reactive powers, generation bus voltage magnitudes, transformers taps etc.).

The essence of the OPF problem resides in reducing the objective function and simultaneously satisfying the Load Flow Equations (equality constraints) without violating the (inequality constraints), which are the Physical System Limits at all generator buses and Operating System Limits at load buses [4].

\subsection{Objective Function:}

The most commonly used objective in the OPF problem formulation is the minimization of the total cost of real power generation. The individual costs of each generating unit are assumed to be function, only, of active power generation and are represented by quadratic curves of second order $[4,7]$. The objective function for the entire power system can then be written as the sum of the quadratic cost model at each generator:

$F(x)=C P_{\text {Total }}=\sum_{i=1}^{N G} C P_{i}=\sum_{i=1}^{N G}\left(a_{i}+b_{i} \cdot P g_{i}+c_{i} \cdot P g_{i}^{2}\right)$

Where:

NG is number of generation including the slack bus.

Pgi is the generated active power at bus-i.

ai, bi and ci are the unit costs curve for ith generator. 


\subsection{Types of Equality Constraints:}

While minimizing the cost function, it is necessary to make sure that the generation still supplies the "load demands (Pd) plus losses in transmission lines". Usually the Power Flow equations are used as equality constraints:

$$
\left[\begin{array}{l}
\Delta P_{i} \\
\Delta Q_{i}
\end{array}\right]=\left[\begin{array}{l}
P_{i}(V, \theta)-\left(P g_{i}-P d_{i}\right) \\
Q_{i}(V, \theta)-\left(Q g_{i}-Q d_{i}\right)
\end{array}\right]=0
$$

Where Active and Reactive Power injection at (bus i) are defined in the following equation:

$$
\begin{aligned}
& P_{i}(V, \theta)=V_{i} * \sum_{j=1}^{N}\left[V_{j} Y_{i j} * \cos \left(\delta_{i}-\delta_{j}-\theta_{i j}\right)\right] \\
& Q_{i}(V, \theta)=V_{i} * \sum_{j=1}^{N}\left[V_{j} Y_{i j} * \sin \left(\delta_{i}-\delta_{j}-\theta_{i j}\right)\right]
\end{aligned}
$$

OR:

$$
\begin{aligned}
& P_{i}(V, \theta)=\sum_{j=1}^{N B} V_{i} \cdot V_{j} \cdot\left(g_{i j} \cos \theta_{i j}+b_{i j} \sin \theta_{i j}\right), i=2, N B \\
& Q_{i}(V, \theta)=\sum_{j=1}^{N B} V_{i} \cdot V_{j} \cdot\left(g_{i j} \sin \theta_{i j}-b_{i j} \cos \theta_{i j}\right), i=N P V+1, N B
\end{aligned}
$$

Where:

Yij is the Bus Admittance

gij is the Conductance, and bij is the Susceptance

$V i$ is voltage magnitude at the bus $i$ and $\theta i j$ is the bus voltage phase angle.

The real power balance and reactive power balance are the most important in OPF and they considered as Equality Constraints [7].

\subsection{Types of Inequality Constraints:}

The inequality constraints of the OPF reflect the limits on physical devices in the power system and the operating limits created to ensure system security. The most usual types of inequality 
constraints are upper bus voltage limits at generations and load buses, lower bus voltage limits at load buses, var. limits at generation buses, maximum active power limits corresponding to lower limits at some generators, maximum line loading limits and limits on tap setting and phase shifter. The inequality constraints on the problem variables considered include $[4,7]$ :

- Upper and lower bounds on the active generations (Real Power) at generator buses:

$$
\text { Pgi min } \leq \text { Pgi } \leq \text { Pgi max, where }(i=1, N G)
$$

- Upper and lower bounds on the (Reactive Power) generations at generator buses and reactive power injection at buses with VAR compensation:

$$
\text { Qgi } \min \leq \text { Qgi } \leq \text { Qgi max, where }(i=1, N P V)
$$

- Upper and lower bounds on the voltage magnitude at the all buses:

$$
V i \min \leq V i \leq V i \max , \text { where }(i=1, N B)
$$

- Upper and lower bounds on the bus voltage phase angles:

$$
\theta i \min \leq \theta i \leq \theta i \max , \text { where }(i=1, N B)
$$

- Upper and lower bounds on branch MW/MVAR/MVA flows may come from thermal ratings of conductors, or they may be set to a level due to system stability concerns:

$$
\left|S_{i j}\right|^{2} \leq S \max _{i j}{ }^{2}
$$

Finally, the generalized objective function $\mathrm{F}$ is a non-linear, and the number of the equality and inequality constraints increase with the physical size of the power distribution systems. Different applications of a conventional optimization technique such as the gradient-based algorithms to a large power distribution system with a very non-linear objective functions and great number of constraints are not good enough to solve this OPF problem. Because it depend on the existence of the first and the second derivatives of the objective function and on the well computing of these derivative in large search space [4]. 


\section{Project Case Study Using OPF Methodology}

\subsection{Discussion and Theory:}

In this project the most optimal solution of optimal power flow (OPF) incorporating wind generation cost was studied, to supply power to a new residential compound load located at the outskirts of an industrial area for three different scenarios. This domestic load is typical of long rural line with isolated load area.

An interconnected network is generally found in more industrial or urban areas and would have almost multiple connections to other power supply. The benefit of interconnected model is that in case of a fault and/or maintenance a small area of network would be isolated and the rest kept on supply. This represent the scenario one of our case study to feed both the industrial area as well as the long rural line domestic load in the village. However, the challenging in our case study that we have to incorporate a wind generation unit as one type of green energy, that are currently being considered as an alternative source of power, to feed this long rural line for the domestic load without effecting in the total generation cost.

A case study conducted for three different scenarios incorporating wind generation cost to feed this long rural line for the domestic load. The results of OPF shows that incorporating wind generation cost as renewable energy source with the entire power system will have a minimum generation cost and minimum transmission losses even if the wind generation cost assumed to be the most expensive one comparing with other conventional generation units.

In this project, it's succeeded to have the required code to implement the Algorithm of the Power Flow using the FDPF and find the maximum mismatch of the real and reactive power for any number of buses and let the algorithm to converge. This program succeeded to optimize the best solution for three different scenarios by using (fmincon) as one of optimization tools to achieve the minimum total cost function of generating units and minimum transmission losses. 
ISO would like to minimize the total cost incurred to purchase real power as required to serve the load(s) and supply for losses in the transmission system. This solution must satisfy physical and operational criteria as set by physical characteristics and the law of the land.

The variables at hand and segregate them as those that we may wish to control (control variables) and those that assume values as a result of settings of the control variables and the physical system (dependent variables).

\section{List of variables:}

PG - Real power output of generators

$Q G$ - Reactive power output of generators

VG - Magnitude of Voltages set at the terminals of generators

VL - Magnitude of Voltages set at load buses

$\delta$ - Phase angles of all Bus voltages phasors

\section{List of constraints characterizing the physical system and loads:}

- $(r, x, z l, y l$ and $y)$ - Transmission line resistance, inductive reactance, complex impedance, and complex admittance and shunt line charging capacitive admittance.

- (YB): System Admittance matrix in the bus frame of reference (complex).

- (PD, QD) - Real and Reactive power drawn at buses by connected loads.

Now, from the above, we could identify the objective and constraints:

\section{Objective Function:}

The cost of real power from the ith generator is specified as:

$C P i=\Sigma(a i+b i . P G i+c i . P G i 2)$;

The total cost incurred by the system operator at the energy control centre would be equal to:

$C P=\Sigma C P i=\sum i(a i+b i \cdot P G i+c i \cdot P G i 2)$ 
So, the objective of the problem would then be:

Minimize: $C P=\Sigma C P i=\sum i(a i+b i \cdot P G i+c i \cdot P G i 2)$

\section{Constraints}

Power Balance Transmission System Constraints at every Bus:

PGi $-P D i-P i(V, \delta)=0$ Real Power Balance

$Q G i-Q D i-Q i(V, \delta)=0$ Reactive Power Balance

Physical Device Limits at Generators:

PGi $\min <P G i<P G i \max$

QGi $\min <Q G i<$ QGi max

VGi $\min <$ VGi $<$ VGi $\max$

System Operating Limits at Load Buses:

VLi $\min <$ VLi $<$ VLi max

$\delta_{1}{ }^{\circ}=0^{\circ}$

\subsection{PROJECT PROPOSAL (CASE STUDY):}

Selecting the most optimal way (OPF) to supply power to a new residential compound load located at the outskirts of an industrial area. The area is settled for three big industrial facilities with a bulky load supplied by two generation stations, one from the north (low generation cost) and the other one in the south (high generation cost) of the industrial area. Now, the industrial area authority decided to build a new village far from the industrial area to the south west direction. Also, a transmission line will be built to connect the industrial area and residential village (compound) with a fixed capital cost. 
This project is studying three (3) different scenarios:

1. PROPOSAL-1: Feeding the Residential load (Village) from two generating units, as shown in Fig.10. The project studying how to optimize the load sharing between the two generators with consideration that the nearest one to the Village has (high Generation Cost but with less power losses) and the other far one has (low Generation Cost but with more power losses) in the transmission system.

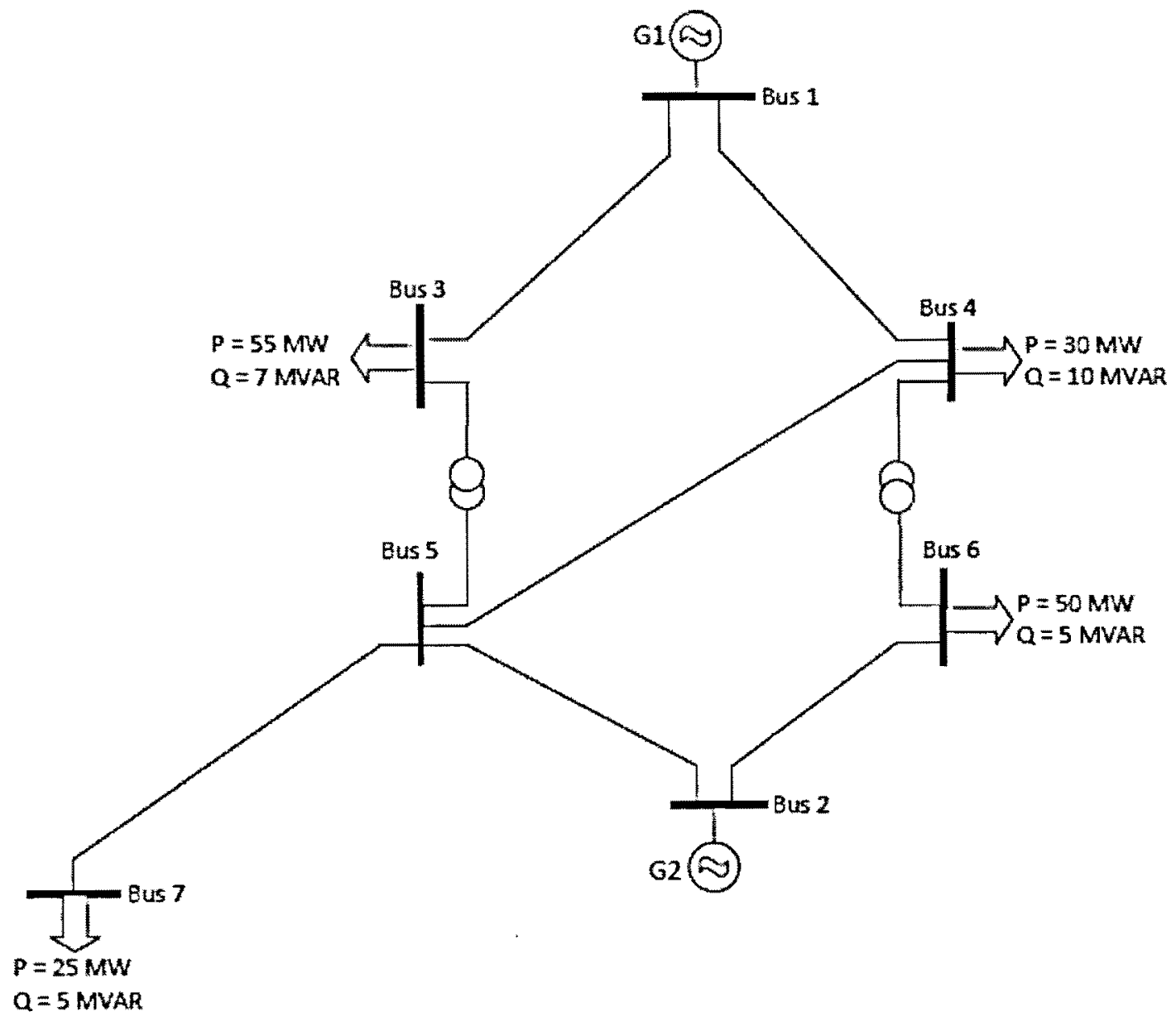

Figure 10: OPF Case Study (Scenario-1) for feeding a new residential load from the same generating units of the Industrial Area 
2. PROPOSAL-2: Installing a Wind Generator (as a good example for the Green Energy) beside the Village to feed the Residential Load, while keeping the transmission line totally disconnected from the Industrial Area, as shown in Fig.11. Then, start to optimize the Objective Function which is the Total Generation Cost.

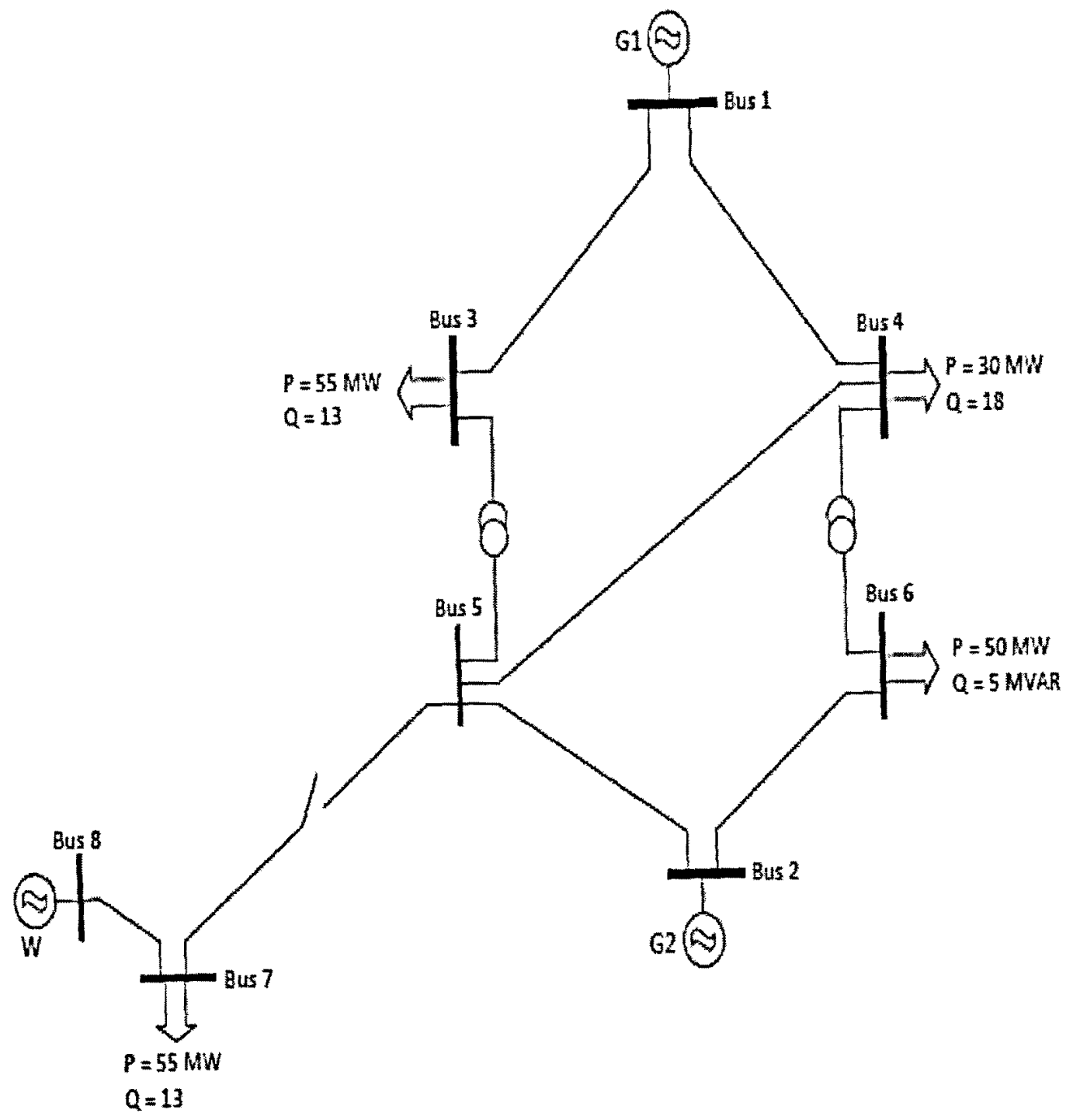

Figure 11: OPF Case Study (Scenario-2) for feeding a new residential load from a Wind Generation Unit with disconnected T.L with other generating units of the Industrial Area 
3. PROPOSAL-3: Optimize the Power Flow with consideration that the two Generation Stations beside the Industrial Area and the Wind Generator beside the Village will be connected with same Power System Network, and the Project studies how to optimize the load sharing between all the Industrial and Residential loads, as shown in Fig.12.

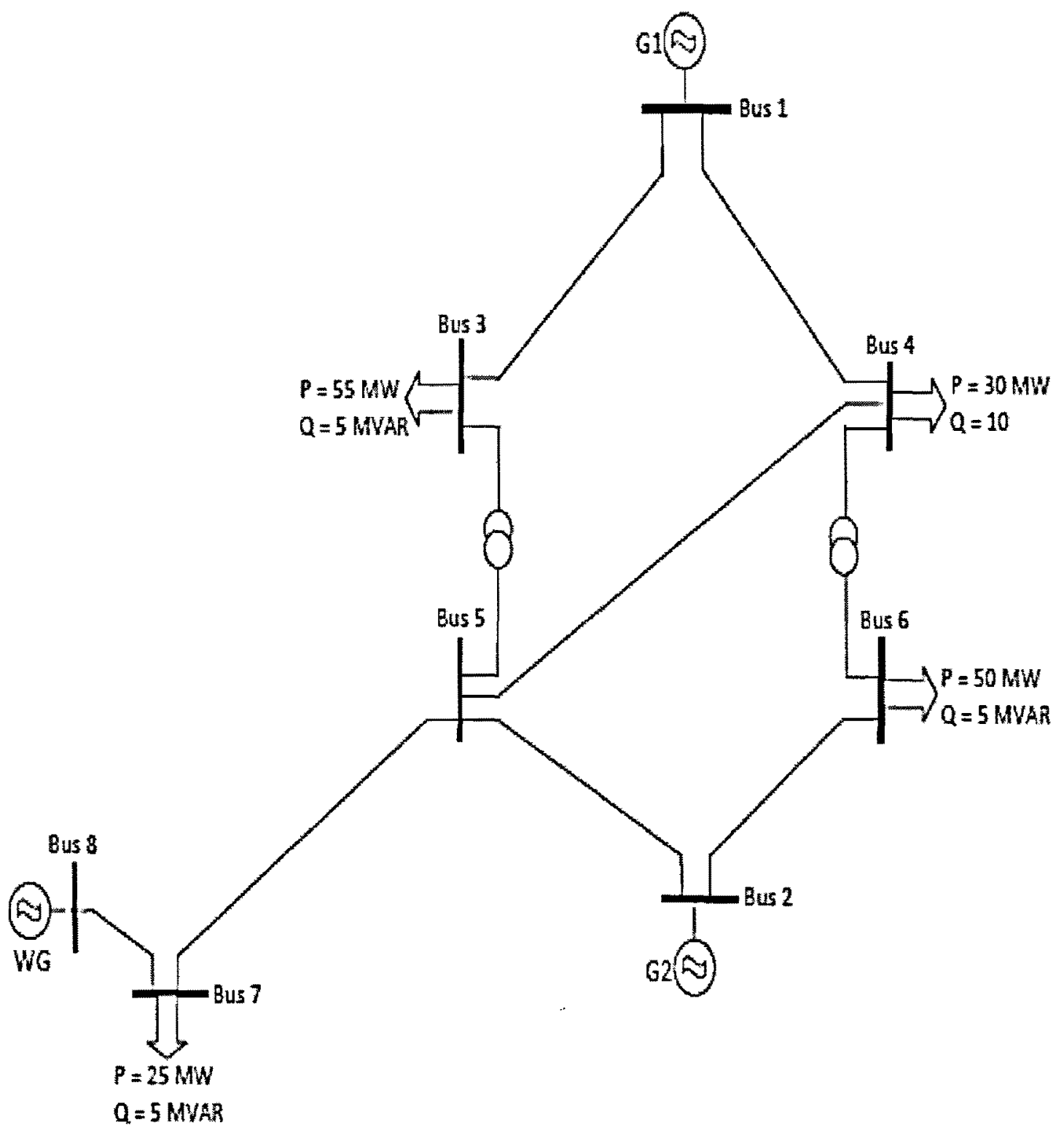

Figure 12: OPF Case Study (Scenario-3) for feeding a new residential load from the entire power system with consideration of the Wind Generation Cost 


\subsection{Project Result Analysis:}

A case study conducted for all the three different scenarios incorporating wind generation cost, as shown in Table 2.

Table 2: Test Results Analysis for Three Different Scenarios (all results attached in the Appendix)

\begin{tabular}{|l|c|c|c|}
\hline \multicolumn{1}{|c|}{ RESULTS } & PROPOSAL-1 & PROPOSAL-2 & PROPOSAL-3 \\
\hline TOTAL REAL GENERATION (MW) & 176.926560 & 172.824448 & 172.523911 \\
\hline TOTAL REAL GENERATION (MW) & 160.000000 & 160.000000 & 160.000000 \\
\hline TOTAL TRANSMISSION LOSS (MW) & 16.926560 & 12.824448 & 12.523911 \\
\hline TOTAL COST (\$) & $64,768.2154$ & $73,689.4818$ & $50,892.0832$ \\
\hline
\end{tabular}

The results of OPF show that incorporating wind generation unit as renewable energy source with the entire power system will outcome to have a minimum generation cost and minimum transmission losses for the entire power system, as shown in Fig. 13 and Fig. 14.

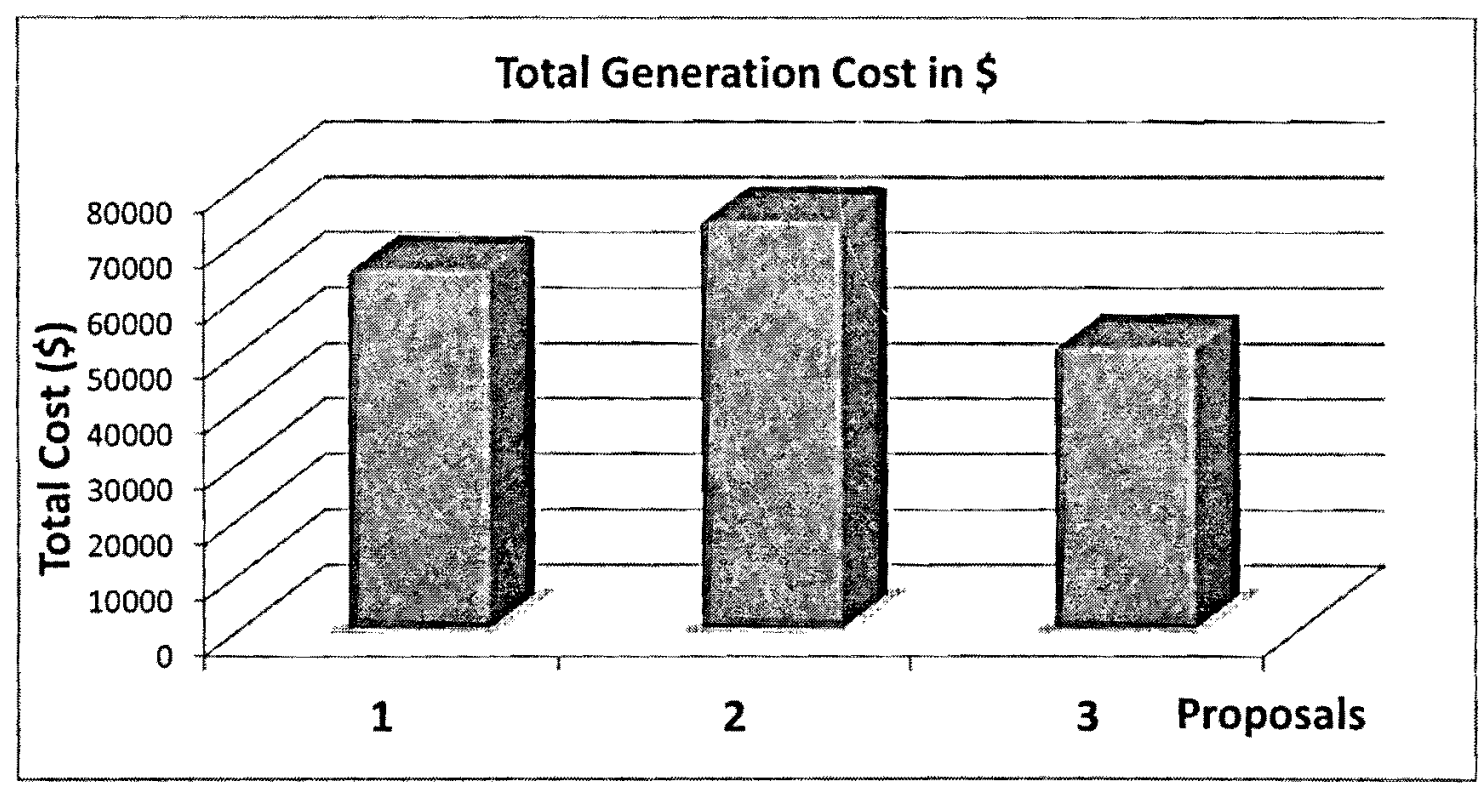

Figure 13: Comparison of Total Generation Cost (\$) based on OPF results 


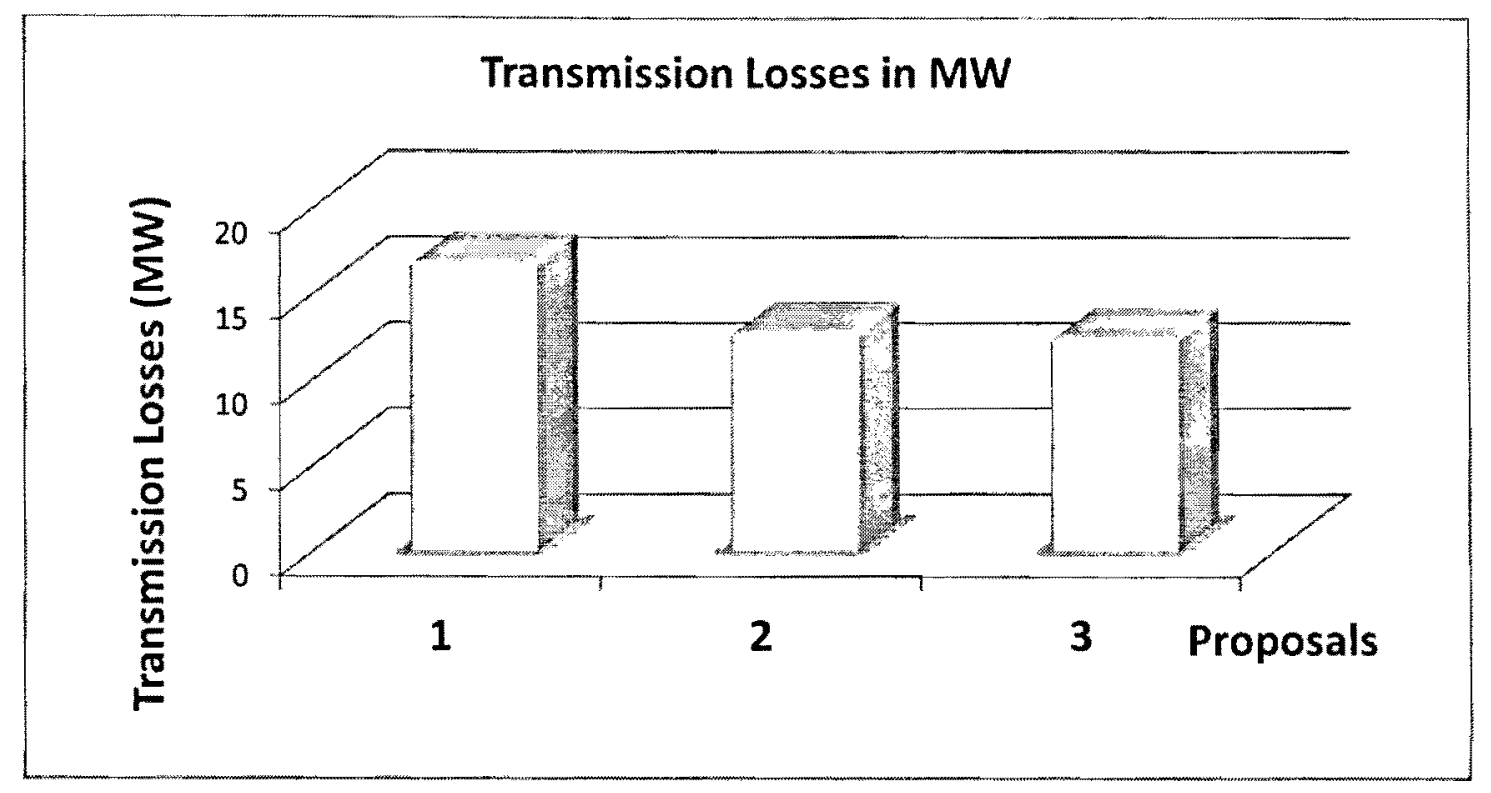

Figure 14: Comparison of Transmission Losses (MW) based on OPF results

Optimal Power Flow (OPF) problem was solved in this project by using MATLAB optimization method and technique on computer. The toolbox (fmincon) has become standard practice to solve a lot of optimization problems. This toolbox from MATLAB has three algorithms, with several options for Hessians, including fmincon trust region reflective algorithm, fmincon active set algorithm, and fmincon interior point algorithm.

The Project used fmincon Optimization Toolbox from the MATLAB to optimize the objective function which is the total generation cost. It was clear that the power transmission losses will account for more Power generation cost. The constraints and the bounds of the optimization problem were the normal physical limits for operating any power system. All the test results of the three different scenarios are attached in the Appendix for the minimum generation cost and transmission losses for the entire power system. 


\section{Conclusion and Future Work}

The OPF problem is the Optimal Power Flow for a power system operation with an objective function, Total Generation Cost, is optimized while satisfying set of system operating constraints.

OPF has been widely used in power system operation and load flow planning. The OPF is a nonlinear, non-convex, large-scale, static optimization problem with both continuous and discrete control variables. Mathematical programming approaches, such as linear, and nonlinear programming, and interior point methods have been used for the solution of the OPF problem.

The challenging was in our case study to incorporate a wind generation unit as one type of green energy, to feed this long rural line for the domestic load without effecting in the total generation cost. A case study conducted as per the achieved results mentioned above, for all the three different scenarios incorporating wind generation cost. The results of OPF shows that incorporating wind generation unit as renewable energy source with the entire power system will have a minimum generation cost and minimum transmission losses for the entire power system even if the wind generation cost assumed to be the most expensive one comparing with other conventional generation units.

One of the most important challenges in the current and coming years is the optimal power flow (OPF) with consideration of the wind generation cost. The wind generation is considered as dynamic optimal power flow (DOPF) which is a typical complex, multi-constrained, nonconvex, non-linear programming problem.

Green Energy is created from natural resources that do not cause harmful pollution to Earth's surface or atmosphere. With the concern of global warming and reducing the natural resources, environmentally friendly alternatives are needed. The different types of green energy that are currently being considered as alternative sources of power could be studied in the future work 
with consideration of the generation cost and its effect on the OPF of the entire power system. That's why; there are a lot of challenges of adhering standards, technology and cost challenges.

Using Genetic Algorithms (GA) as another MATLAB optimization toolbox in the future works for the same case study with all different scenarios may be could achieve better results than fmincon toolbox. The application of genetic algorithms (GA) in solving the OPF problem, overcomes the limitations of the conventional approaches in the modeling of non-convex cost functions, discrete control variables (such as switchable shunt devices, transformer tap positions, and phase shifters, further complicates the problem solution.), and prohibited unit operating zones. GA has been developed as a biological approach to search and optimization. They consist of a population of bit strings transformed by three genetic operators: selection, crossover and mutation. Each string (chromosome) represents a possible solution for the problem being optimized and each bit (or group of bits) represents a value for some variable of the problem (gene). These solutions are classified by an evaluation function, giving better values, or fitness, to better solutions.

There are a lot of well-known features of GA as an optimization tool for solving OPF problems:

1. GA does not require "well behaved" objective functions and allow simple handling of discontinuities and non-linearity, which are hard to include in pure mathematical programming methods.

2. Using GA will not obtain only one "Optimal solution, but a large group of solutions

3. GA is well adapted for distributed implementations, allowing computation time to be drastically reduced. The test results in the existing GA-OPF models are limited to small problems, and usually simple fast decoupled load flow (FDLF) is used with no PV-PQ bustype switching, since generator reactive capabilities are incorporated in the functional operating constraints. 


\section{References}

[1] Hermann W. Dommel, and William F. Tinney, "Optimal Power Flow Solutions", IEEE transactions on Power Apparatus and Systems, PAS-87, No.10, October 1968.

[2] M. A. Abido, "Optimal power flow using particle swarm optimization", Electrical Power and Energy Systems 24 (2002) 563-571, ELSEVIER Science Ltd., 2002.

[3] Edmea C. Baptista, Edmarcio A. Belati, Geraldo R.M. da Costa, "Logarithmic barrieraugmented Lagrangian function to the optimal power flow problem", Electrical Power and Energy Systems, Elsevier Ltd., 2005.

[4] Tarek BOUKTIR, and Linda SLIMANI, "Optimal Power Flow of the Algerian Electrical Network using an Ant Colony Optimization Method", Leonardo Journal of Sciences, ISSN 1583-0233, 2005.

[5] William H. Kersting, "Distribution System Modeling and Analysis", CRC Press, 2002.

[6] William Stevenson and John Grainger, "Power System Analysis", McGraw-Hill Science Engineering, 2005.

[7] Venkatesh B, "Power System Optimization" in ECE website, EE8604, RU, 2009.

[8] Energy Control Center Website: http://www.scribd.com/doc/20328427/Ee1401-PowerSystem-Operation-and-Control-Energy-Control-Center-Safety; Accessed on April $28^{\text {th }}, 2011$.

[9] F. Bassi, C. Bruno, P. Crisafulli, G. Giannuzzi, L. Gorello, S. Pasquini, M. Pozzi, and R. Zaottini, "Optimal Power Flow procedure for real-time security and economic re-dispatching in a market structure", IEEE, 2009.

[10] Lee K. Y., Park Y. M., and Ortiz J. L., "A United Approach to Optimal Real and Reactive Power Dispatch", IEEE Transactions on Power Systems, Vol. PAS-104, p. 1147-1153, 1985.

[11] Sun DI, Ashley B, Brewer B, Hughes A, Tinney WF, "Optimal power flow by Newton 
approach", IEEE Trans Power Apparatus System; PAS-103(10):2864-75, 1984.

[12] Santos A, da Costa GR, "Optimal power flow solution by Newton's method applied to an augmented Lagrangian function", IEE Proc Gener Transm Distrib; 142(1):33-36, 1995.

[13] Yan X, Quintana VH, "Improving an interior point based on OPF by dynamic adjustments of step sizes and tolerances", IEEE Trans Power System; 14(2):709-17, 1999.

[14] Momoh JA, Zhu JZ, "Improved interior point method for OPF problems", IEEE Trans Power System; 14(3):1114-20, 1999.

[15] Burchett RC, Happ HH, Vierath DR, "Quadratically convergent optimal power flow", IEEE Trans Power Apparatus System; PAS-103:3267-76, 1984.

[16] Aoki K, Nishikori A, Yokoyama RT, "constrained load flow using recursive quadratic programming", IEEE Trans Power Apparatus System; 2(1):8-16, 1987.

[17] Sasson M., "Nonlinear Programming Solutions for load flow, minimum loss, and economic dispatching problems", IEEE Trans. on Power Apparatus and Systems, vol. Pas-88, No. 4, 1969.

[18] Alsac O, Stott B, "Optimal Load Flow with steady state security", IEEE Trans Power Apparatus System; PAS-93:745-51, 1974.

[19] Shoults R, Sun D, "Optimal power flow with based on P-Q decomposition", IEEE Trans Power Apparatus System; PAS-101(2):397-405, 1982.

[20] Happ HH, "Optimal power dispatch: a comprehensive survey", IEEE Trans Power Apparatus System; PAS-96:841-54, 1977.

[21] Mamandur KRC, "Optimal control of reactive power flow for improvements in voltage profiles and for real power los minimization", IEEE Trans Power Apparatus System; PAS100(7):3185-93, 1981.

[22] Abou El-Ela AA, Abido MA, "Optimal operation strategy for reactive power control, 
Modeling, simulation and control", part A, vol. 41(3), AMSE Press, 1992.

[23] Stadlin W, Fletcher D, "Voltage versus reactive current model for dispatch and control", IEEE Trans Power Apparatus System; PAS-101(10):3751-8, 1982.

[24] Mota-Palomino R, Quintana VH, "Sparse reactive power scheduling by a penalty-function linear programming technique", IEEE Trans Power Apparatus System; 1(3):31-39, 1986.

[25] Rahli M, Pirotte $P$, "Optimal load power flow using sequential unconstrained minimization technique (SUMT) method under power transmission losses minimization", Electrical Power System Res;52:61-64, 1999.

[26] Fletcher R, "Practical Methods of Optimization", John Willey and Sons, 1986.

[27] Edmea C. Baptista, Edmarcio A. Belati, Geraldo R.M. da Costa, "Logarithmic barrieraugmented Lagrangian function to the optimal power flow problem", Electrical Power and Energy Systems, 27 (2005) 528-532, 2005.

[28] B. Venkatesh, G. Sadasivam, and M. Abdullah Khan, "A New Optimal Power Scheduling Method for Loss Minimization and Voltage Stability Margin Maximization Using Successive Multi-Objective LP Technique", IEEE transactions on Power Systems, VOL. 15, No.2, May 2000.

[29] Bouktir T., Belkacemi M., Zehar K., "Optimal power flow using modified gradient method", Proceedings ICEL'2000, U.S.T. Oran, Algeria, p. 436-442, 2000.

[30] Types of Green Energy Website: http://www.ehow.com/about 4702917 types-greenenergy.htmiltixzz1Naefs4aN; Accessed on April 16 ${ }^{\text {th }}, 2011$.

[31] L.B. Shi, C. Wang, L. Z. Yao, L.M. Wang, Y. X. Ni, and B. Masoud, "Optimal Power Flow with Consideration of Wind Generation Cost", International Conference on Power System Technology, IEEE 2010.

[32] T. Ackermann, "Wind Power in Power System", Chi Chester: Wiley, 2005. 
[33] Y. Liu, T. Shang, "Economic Dispatch of power system incorporating wind power plant", in Proc. 1991 power Engineering Conference, pp. 159-162, 1991.

[34] J. B. Cardell, and C. L. Anderson, "Estimating the System Costs of Wind Power Forecast Uncertainty", IEEE transactions, IEEE 2009.

[35] Haiyan Chen, Jinfu Chen, and Xianzhong Duan, "Multi-Stage Dynamic Optimal Power Flow in Wind Power Integrated System", IEEE transactions, IEEE/PES Transmission and Distribution Conference \& Exhibition, 2005.

[36] R.A. Jabr, B.C.Pal, "Intermittent wind generation in optimal power flow dispatching", IEEE transactions, The Institution of Engineering and Technology, 2008.

[37] Gonggui Chen, Jinfu Chen, and Xianzhong Duan, "Power Flow and Dynamic Optimal Power Flow Including Wind Farms", IEEE Xplore, 2010.

[38] Cost Comparisons of Energy supply technologies Website:

www.unenergy.org/Popup\%20pages/Comparecosts,html, Accessed on April $20^{\text {th }}, 2011$. 


\section{Appendix:}

\section{PROJECT CODE:}

The MATLAB code used (fmincon) Optimization Toolbox which used in the OPF project and structured as below:

1. The program of the project named "Proj.m". This works on files "prop1.i" and "prop3.i". These are the proposals 1 and 3, as show in Fig.(10) and Fig.(12).

2. The program "Proj2.m" works on "prop2.i". This is proposal 2. The program will work on proposal 2 (Which has an open Transmission Line) without any outside calculations. The "Proj2.m" designed to work on it. Also, it can work on the other two proposals as well.

3. In the output files, you could find at the end the Total Transmission Losses and the Total Generation Cost.

4. Compare between the proposals using these values. The results was showing that the generation cost of proposal 3 (Scenario-3) is the lowest cost $(\$ / M W)$ and lowest transmission losses.

\subsection{How Program Work (Brief Write-up):}

The Programs (Proj.m) and (Proj2.m) will read input data from the input data files of the proposals of the different systems, then build the (Admittance Matrix) and the ( $B^{\prime}$ and $B^{\prime \prime}$ Matrices) for these systems.

Proj1.m will work for the proposals ( 1 and 3 ) by running the Load Flow algorithm using the Fast Decoupled Load Flow (FDLF) Algorithm. This will generate initial conditions for the Optimization process to start with.

Proj2.m will work for proposal 2 and it will not run the Load Flow Algorithm as the system will then contain two isolated islands and values of unity will be assigned to Load Voltage 
Magnitudes and values of zero will be assigned to Voltage Angles, Real Power and Reactive Power initially. Consequently it will not contain parts 6 and 7.

Then both programs will execute part_ 8 by running the Optimization using the (fimincon) function which applies non-linear constrained optimization. In this part upper and lower bounds for the Variables.

An external function called (Constraints.m) will be used to apply the non-linear constraints for the Power Balance Equations. After that the Transmission Line Flows will be done and the Output files will be created containing all the calculations for the system including the Transmission Losses and the Total Generation Cost.

\subsection{Project Code Description:}

Part_1: Read Data File and Input System Data \& Details

Part_2: Formation Y_Bus(YB)

1. \% Transformer Part

2. \% Transmission Line Part

3. \% Shunt Capacitors Part

4. \% Shunt Reactors Part

Part_3: $Y$ bus partitioning (Y\&Th)

Part_4: Formation of B prime (BP) Matrix

Part_5: Formation of B double prime (BDP) Matrix

Part_6: Starting FDLF Algorithm

FDLF Algorithm Conditions :( IT<=ITmax \& \& ERR $>=$ TOLER/Pbase) to enter Algorithm loop

1. Step1: Calculate $(P)$ at all buses

2. Step2: Calculate (DelP) $=(P G-P D-P)$ at all buses except Slack Bus

3. Step3: Calculate (DelDel)at all buses except Slack Bus 
4. Step4: Update the value of Delta (DEL)

5. Step5: Calculate (Q)at all buses

6. Step6: Calculate (DelQ) $=(Q G-Q D-Q)$ at all buses except Gen. Buses

7. Step7: Calculate (DelV) at all buses except Generator Buses

8. Step8: Update the value of $(V)$

9. Step9: Check the Convergence: $E R R=\max (P M I S, Q M I S)$

*Note: (1): Add one to the number of iterations (IT=IT+1)

(2): Check for Convergence: If still (ERR>TOLER/Pbase) \& (IT<3), then GO BACK to Step1 again, till it will be converge or be finished the 3-iterations and stop.

Part_7: Calculate Real and Reactive Power Generated

Part_8: Run Optimization

- Set Lower and Upper Bounds

- Initial Conditions

- Linear Constraints

* Note: The non-linear constraints are calculated by the function Constraints.m

- Defining Objective

- Invoking the 'fmincon' routine

- Updating variables

Part_9: Calculate Transmission Line Power Flow

$>$ 1st: Real and Reactive (From Flow) and (To Flow) Part

$>$ 2nd: Power Flow (MVA) per Circuit Part

Part_10: Generate Output file to write the output data, summary of the results, Transmission Losses and Total Cost 


\section{PROJECT RESULT ANALYSIS:}

\section{Proposal-1 Results:}

INRUT FILE NAME: prop1.i

OUTPUT FILE NAME: prop1.0

SYSTEM: IEEE_6_BUS_SYSTEM

YEAR : 2011

CASE : PEAK LOAD

NUMBER: 100

NUMBER OF BUSES : 7

SLACK BUS NUMBER : 1001

NUMBER OF GENERATORS : 2

NUMBER OF LOAD BUSES : 5

NUMBER OE TRANSFORMERS : 2

NUMBER OF TRANSMISSION LINES : 6

NUMBER OF SHUNT CAPACITORS : 1

NUMBER OF SWITCHABLE CAPACITORS :1

NUMBER OF SHUNT REACTORS : 1

SLACK BUS VOLATGE : 1.0500

TOLERANCE (MW): $: 0.0100$

BASE MVA $60: 100.0000$

MINIMUM LOAD BUS VOLTAGE : 0.9000

MAXIMUM LOAD BUS VOLTAGE : 1.1000

MAXIMUM NUMBER OF ITERATIONS : 3

$\begin{array}{llllll}\text { ITERATION }: 1 & \text { MAX P MISMATCH }: 0.525000 & \text { P ITERATION IS PERFORMED } \\ \text { ITERATION }: 1 & \text { MAX Q MISMATCH }: 0.345641 & \text { Q ITERATION IS PEREORMED } \\ \text { ITERATION }: 2 & \text { MAX P MISMATCH }: 0.150826 & \text { P ITERATION IS PERFORMED } \\ \text { ITERATION }: 2 & \text { MAX Q MISMATCH }: 0.153852 & \text { Q ITERATION IS PERFORMED } \\ \text { ITERATION }: 3 & \text { MAX P MISMATCH }: 0.116439 & \text { P ITERATION IS PEREORMED } \\ \text { ITERATION }: 3 & \text { MAX Q MISMATCH }: 0.126193 & \text { Q ITERATION IS PEREORMED }\end{array}$

SUMMARY OE THE RESULTS

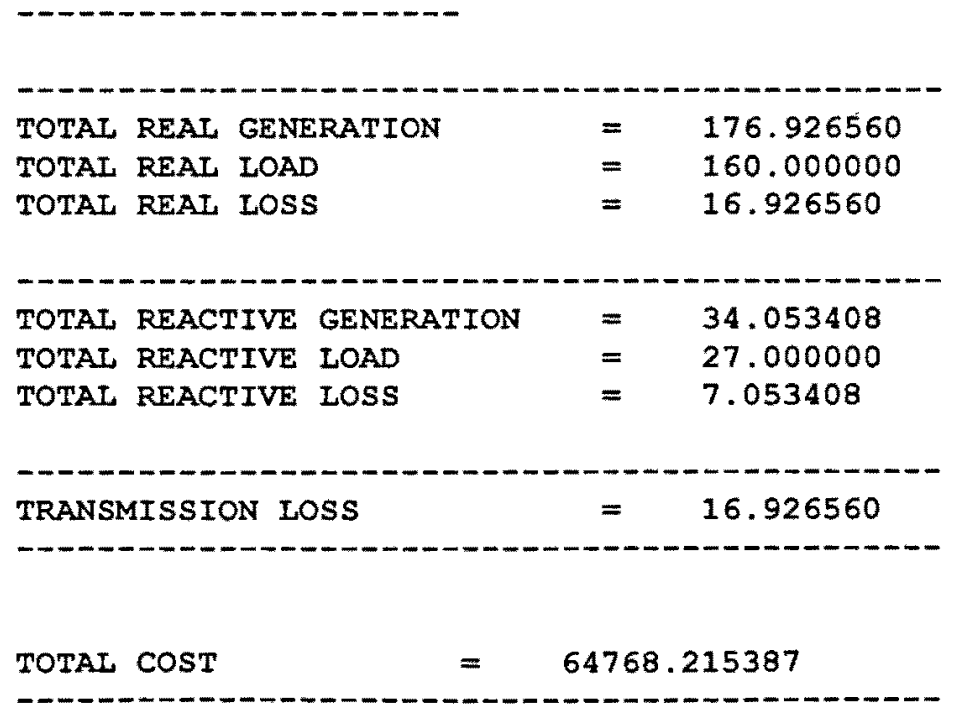




\section{Proposal-2 Results:}

INPUT FILE NAME: prop2.i

OUTPUT FILE NAME: prop2.0

SYSTEM: IEEE_6_BUS_SYSTEM

YEAR : 2011

CASE : PEAK LOAD

NUMBER: 100

NUMBER OE BUSES : 8

SLACK BUS NUMBER : 1001

NUMBER OF GENERATORS : 3

NUMBER OF LOAD BUSES : 5

NUMBER OF TRANSEORMERS : 2

NUMBER OF TRANSMISSION LINES : 6

NUMBER OF SHUNT CAPACITORS : 0

NUMBER OF SWITCHABLE CAPACITORS :0

NUMBER OF SHUNT REACTORS : 0

SLACK BUS VOLATGE : 1.0500

TOLERANCE (MW) : 0.0100

BASE MVA $60: 100.0000$

MINIMUM LOAD BUS VOLTAGE : 0.9000

MAXIMUM LOAD BUS VOLTAGE : 1.1000

MAXIMUM NUMBER OF ITERATIONS : 3

DETAILED OUTPUT IN FER UNIT

SUMMARY OF THE RESULTS

SUMMARY OF IHE RESULTS

$\begin{array}{lll}\text { TOTAL REAL GENERATION } & =172.824448 \\ \text { TOTAL REAI LOAD } & =160.000000 \\ \text { TOTAL REAL LOSS } & =12.824448\end{array}$

$\begin{array}{lll}\text { TOTAL REACTIVE GENERATION } & =64.964830 \\ \text { TOTAL REACTIVE LOAD } & =27.000000 \\ \text { TOTAL REACTIVE LOSS } & =37.964830\end{array}$

\begin{tabular}{ll} 
& $=12.824448$ \\
TRANSMISSION LOSS & $=13689.481848$ \\
\hline
\end{tabular}




\section{Proposal-3 Results:}

INEUT FILE NAME: prop3.i

OUTPUT FILE NAME: prop3.0

SYSTEM: IEEE_6_BUS_SYSTEM

YEAR : 2011

CASE : PEAK LOAD

NUMBER: 100

NUMBER OF BUSES : 8

SLACK BUS NUMBER : 1001

NUMBER OF GENERATORS : 3

NUMBER OF LOAD BUSES : 5

NUMBER OF TRANSFORMERS : 2

NUMBER OF TRANSMISSION LINES : 7

NUMBER OF SHUNT CAPACITORS : 0

NUMBER OF SWITCHABLE CAPACITORS :0

NUMBER OF SHUNT REACTORS : 0

SLACK BUS VOLATGE : 1.0500

TOLERANCE (MW): $: 0.0100$

BASE MVA $60: 100.0000$

MINIMUM LOAD BUS VOLTAGE : 0.9000

MAXIMUM LOAD BUS VOLTAGE : 1.1000

MAXIMUM NUMBER OE ITERATIONS : 3

$\begin{array}{llllll}\text { ITERATION }: 1 & \text { MAX P MISMATCH } & : 0.525000 & \text { P ITERATION IS PERFORMED } \\ \text { ITERATION }: 1 & \text { MAX Q MISMATCH }: 0.358438 & \text { Q ITERATION IS PERFORMED } \\ \text { ITERATION }: 2 & \text { MAX P MISMATCH }: 0.097845 & \text { P ITERATION IS PERFORMED } \\ \text { ITERATION }: 2 & \text { MAX Q MISMATCH }: 0.128541 & \text { Q ITERATION IS PEREORMED } \\ \text { ITERATION }: 3 & \text { MAX F MISMATCH }: 0.067734 & \text { P ITERATION IS PERFORMED } \\ \text { ITERATION }: 3 & \text { MAX Q MISMATCH }: 0.091209 & \text { Q ITERATION IS EERFORMED }\end{array}$

SUMMARY OF THE RESULTS

$-m-m-m-m$

$\begin{array}{lll}\text { TOTAL REAL GENERATION } & =172.523911 \\ \text { TOTAL REAL LOAD } & = & 160.000000 \\ \text { TOTAL REAL LOSS } & = & 12.523911\end{array}$

$\begin{array}{ll}\text { TOTAL REACTIVE GENERATION } & =65.969139 \\ \text { TOTAL REACTIVE LOAD } & =37.000000 \\ \text { TOTAL REACTIVE LOSS } & =38.969139\end{array}$

TRANSMISSION LOSS

IOTAI cost $=$

